\title{
ERS/TSANZ Task Force Statement on the management of reproduction and pregnancy in women with airways diseases
}

\author{
Peter G. Middleton (101, Elisabeth J. Gade², Cristina Aguilera ${ }^{3}$, Lucy MacKillop ${ }^{4}$, \\ Brenda M. Button ${ }^{5}$, Courtney Coleman ${ }^{6}$, Barbara Johnson ${ }^{6}$, \\ Charlotte Albrechtsen ${ }^{7}$, Frank Edenborough ${ }^{8}$, David Rigau ${ }^{9}$, Peter G. Gibson (ib ${ }^{10}$ \\ and Vibeke Backer (1) ${ }^{11}$
}

Affiliations: ${ }^{1} \mathrm{CF}$ Research Group, Ludwig Engel Centre for Respiratory Research, Westmead Institute for Medical Research, University of Sydney, Sydney, Australia. ${ }^{2}$ Dept of Gynecology and Obstetrics, Rigshospitalet, Copenhagen, Denmark. ${ }^{3}$ Dept of Clinical Pharmacology, University Hospital Vall d'Hebron, Barcelona, Spain. ${ }^{4}$ Oxford University Hospitals NHS Foundation Trust, Nuffield Dept of Women's and Reproductive Health University of Oxford, Oxford, UK. ${ }^{5}$ Dept of Medicine, Nursing and Health Sciences, Monash Institute of Medical Research, Monash University, Melbourne Australia. ${ }^{6}$ European Lung Foundation, Sheffield, UK. ${ }^{7}$ Dept of Anaesthetics, Rigshospitalet, Copenhagen, Denmark. ${ }^{8}$ Sheffield Adult Cystic Fibrosis Centre, Northern General Hospital, Sheffield, UK. ${ }^{9}$ Iberoamerican Cochrane Centre, Barcelona, Spain. ${ }^{10}$ Centre for Asthma and Respiratory Diseases, Faculty of Health and Medicine, University of Newcastle, Newcastle, Australia. ${ }^{11}$ Centre for Physical Activity Research, Rigshospitalet and Copenhagen University, Copenhagen, Denmark.

Correspondence: Peter G. Middleton, Westmead Hospital, Ludwig Engel Centre for Respiratory Research, Hawkesbury Road, Westmead, Sydney, NSW 2145, Australia. E-mail: peter.middletondasydney.edu.au

@ERSpublications

Good management of women with airways diseases before, during and after pregnancy is an important area of respiratory medicine, affecting both the mother and child: a statement from the ERS and TSANZ http://bit.ly/2mMwvGZ

Cite this article as: Middleton PG, Gade EJ, Aguilera C, et al. ERS/TSANZ Task Force Statement on the management of reproduction and pregnancy in women with airways diseases. Eur Respir J 2020; 55: 1901208 [https://doi.org/10.1183/13993003.01208-2019].

ABSTRACT This European Respiratory Society/Thoracic Society of Australia and New Zealand statement outlines a review of the literature and expert opinion concerning the management of reproduction and pregnancy in women with airways diseases: asthma, cystic fibrosis (CF) and non-CF bronchiectasis. Many women with these diseases are now living into reproductive age, with some developing moderate-to-severe impairment of lung function in early adulthood. The statement covers aspects of fertility, management during pregnancy, effects of drugs, issues during delivery and the post-partum period, and patients' views about family planning, pregnancy and parenthood. The statement summarises current knowledge and proposes topics for future research, but does not make specific clinical recommendations.

This document was endorsed by the ERS Executive Committee on 10 September, 2019, and by the European Cystic Fibrosis Society on 11 July, 2019, and Thoracic Society of Australia and New Zealand on 24 September 2019.

This article has supplementary material available from erj.ersjournals.com

Received: 19 June 2019 | Accepted after revision: 30 Aug 2019

Copyright OERS 2020 


\section{Introduction}

\section{Outline}

This statement outlines a review of the literature and expert opinion concerning the management of reproduction and pregnancy in women with airways diseases. The statement represents the first collaboration of the European Respiratory Society (ERS) and the Thoracic Society of Australia and New Zealand (TSANZ) to develop such documents.

The statement covers airways diseases: asthma, cystic fibrosis (CF) and non-CF bronchiectasis. Many women with these diseases are now living into reproductive age, with some developing moderate-to-severe impairment of lung function in early adulthood. The statement covers aspects of fertility, management during pregnancy, effects of drugs, and issues during delivery and the post-partum period. Patients' views about family planning, pregnancy and parenthood obtained through an online survey are discussed and summarised.

The statement summarises current knowledge, but does not make specific clinical recommendations. Topics for future research are proposed.

The statement does not discuss the physiological changes occurring in pregnancy, such as the changes in airway physiology, resting ventilation and sleep, which have been summarised elsewhere [1]. The statement does not cover other forms of lung disease, such as pulmonary fibrosis, pulmonary hypertension, gastro-oesophageal reflux-related lung disease or issues with nicotine consumption.

\section{Methods}

This ERS/TSANZ Task Force was composed of respiratory physicians, obstetricians, general practitioners, allied health staff and women with airways diseases. The Task Force received support from ERS methodologists. The European Lung Foundation, in collaboration with patient volunteers, designed an online survey to better understand women's views when living with an airways disease. All co-authors critically revised and approved the final statement and completed conflict of interest forms.

The present ERS/TSANZ statement combines an evidence-based approach with the clinical expertise of the Task Force members, based on both literature search and face-to-face meetings. Literature was searched using MEDLINE, Embase and CINAHL databases, limited to 1995 onwards and English language. An outline of the literature search strategy (1995-2017) is given in the supplementary material. A repeat literature search was undertaken in November 2018 to include the latest publications.

All references from the literature searches were examined by the two co-chairs (P.M. and V.B.), after which a selection of papers was given to the Task Force members who selected the relevant literature. Disagreements were resolved by consensus. The selection was based on the population (pregnant women with asthma, CF or bronchiectasis) and the effects of these diseases on risks of pregnancy-associated complications and miscarriages, breastfeeding, nutritional considerations, lung function, long-term maternal outcomes, and management considerations during pregnancy. There are very few randomised control trials (limited to the management of pregnancy in women with asthma), so the evidence consisted of observational studies (prospective or retrospective), cross-sectional surveys and case series. Other guidelines have also recently been published, which may be helpful to the reader [2]. The current Task Force builds on these other guidelines; however, the National Institute for Health and Care Excellence (NICE) document [2] only concerns intra-partum care, whereas the current document limits the disease groups (i.e. asthma, CF and bronchiectasis), but covers issues before, during and after pregnancy.

The document aims to provide an overview of the literature and current evidence, and does not provide a thorough systematic review and meta-analysis for each topic or recommendations for clinical practice.

\section{Reproduction and conception issues in women with airways disease}

Many chronic respiratory diseases commence early in life and so are present in young adult women trying to conceive. There is sparse research in this field, although impaired fertility has been found in women with asthma [3]. For CF, the rapidly changing clinical status in young adult women [4] complicates comparison of older studies with more current literature, and for bronchiectasis, there are little data available.

\section{Fertility in asthma patients}

Different studies have found varied associations between the presence of asthma and subfertility in women $[3,5,6]$. More recent studies have suggested that asthma negatively influences fertility with increased time to pregnancy and reduced birth rate $[3,6]$. The time to pregnancy in women with asthma increases with maternal age and use of fertility treatment increases especially in those over 35 years of age [3], which may suggest that the severity of the disease or the duration of exposure to low-grade inflammation has a negative influence on fertility. 
Epidemiological data attempting to clarify the relative effects of asthma medications and underlying asthma severity on fertility is inconclusive. GADE et al. [3] found an association between untreated asthma (defined as no regular inhalers) and time to pregnancy, as well as between use of daily inhaled corticosteroid (ICS) and longer time to pregnancy, although it was not possible to differentiate between asthma severity per se and the level of treatment [3]. However, this was not found in a subsequent clinical study [7]. Recently, interesting data from the Screening for Pregnancy Endpoints (SCOPE) study have shown that women with self-reported asthma only using short-acting $\beta_{2}$-agonists (SABAs) had prolonged time to pregnancy and reduced fertility [6], yet those with self-reported asthma who were prescribed ICS had no reduction in fertility. This suggests that undertreatment of asthma with systemic inflammation may reduce fertility [6]. Given this data, women with asthma should be informed of the risk of reduced fertility especially if not on maintenance ICS therapy and particularly above 35 years of age $[7,8]$.

\section{Fertility in CF and bronchiectasis}

The life expectancy of people with CF has been increasing due to improved treatments $[4,9]$, which has resulted in an increasing number of men and women with CF living into adulthood and wanting to have children. In both cases, it is recommended that the partner is tested for cystic fibrosis transmembrane conductance regulator $(C F T R)$ mutations to allow appropriate discussions regarding prenatal testing and pre-implantation genetic diagnosis $[10,11]$.

It is well known that most men with CF (95\%) are infertile because of blockage or absence of the vas deferens, which requires in vitro fertilisation (IVF) intervention for pregnancy [10]. In contrast, although CFTR is expressed in the cervix [12] and the water content of cervical mucous does not show the normal menstrual cycle variation, the fallopian tubes remain patent in the majority of adult women with CF [13]. Fertility in women with CF can be worsened by poor nutrition leading to irregular ovulation or secondary amenorrhoea. A recent multinational survey showed that $35 \%$ of women with CF experienced subfertility compared with $5-15 \%$ in the general population [14]. Older age and pancreatic insufficiency were associated with subfertility, while lung function and body mass index were not associated with subfertility. CF-related diabetes (CFRD) was present in $16 \%$ of women with normal fertility and $23 \%$ of the subfertile group $(p=0.02)$, and those with CFRD were significantly less likely to attempt conception. In cases of reduced fertility, IVF may be necessary [14]. Recently, a French registry study of women with CF who reported a pregnancy between 2001 and 2012 found that 14 out of 29 women with pre-gestational diabetes reported medically assisted conception compared with 51 out of 160 women without CFRD $(\mathrm{p}=0.06)$ [15].

In women with CFRD it is expected that good glycaemic control will improve the ability to conceive and reduce the risk of miscarriage and congenital malformations, as found in pre-conception care for non-CF women with diabetes [16]. Gestational diabetes is common, so current guidelines recommend an oral glucose tolerance test (OGTT) should be performed in all women with CF before pregnancy and repeated during pregnancy [17-19].

In contrast to the knowledge concerning fertility issues in asthma and CF, little is known about these issues in bronchiectasis due to other causes. In general, most clinicians will manage fertility using a similar approach of maximising lung function and nutrition, and minimising chronic infection.

\section{Airways medications summary applicable to all sections}

Continued use of inhaled therapies is critical to the management of airways disease during pregnancy. This section presents tables outlining the commonly used medications for different airways diseases and their impact on the uterus, the fetus and during breastfeeding. No systematic review of the literature was performed; the references were selected by a clinical pharmacologist with expertise in the field based on their relevance and product information from regulatory agencies.

For full details concerning an individual medication, product information is available through the Australian Therapeutic Goods Administration (TGA) [20], European Medicines Agency [21] and US Food and Drug Administration (FDA) [22]. The TGA rates all medications for use during pregnancy and lactation with categories based on perceived risks. It should be noted that the FDA's new Pregnancy and Lactation Labelling Rule removes pregnancy letter categories (A, B, C, D and X), and advocates for communicating information on the benefits and risks of using a drug during pregnancy and lactation [22]. It is included here for completeness. The TGA and FDA categories are summarised in table 1.

\section{Considerations from the Task Force}

Tables 2-5 present the Task Force summaries for airways medications [23-81]. Please note the summaries are not based on randomised controlled trials. 
TABLE 1 Summary of Therapeutic Goods Administration (TGA) and Food and Drug Administration [FDA] categories

TGA category

(A)

(B1)

$(-)$

\section{FDA category}

[A]

[B]

$[\mathrm{C}]$
Drugs taken by a large number of pregnant women, without an increase in the frequency of fetal malformations or harmful effects.

Drugs taken by a limited number of pregnant women, without an increase in the frequency of fetal malformation or harmful effects. Studies in animals have not shown evidence of increased fetal damage.

Drugs taken by a limited number of pregnant women, without an increase in the frequency of fetal malformation or harmful effects. Studies in animals are inadequate or may be lacking.

Drugs taken by a limited number of pregnant women, without an increase in the frequency of fetal malformation or harmful effects. Studies in animals have shown evidence of an increased occurrence of fetal damage, the significance of which is considered uncertain in humans.

Drugs which, owing to their pharmacological effects, have caused or may be suspected of causing harmful effects on the human fetus or neonate without causing malformations. These effects may be reversible.

Drugs which have caused, are suspected to have caused or may be expected to cause an increased incidence of human fetal malformations or irreversible damage. These drugs may also have adverse pharmacological effects.

Drugs which have such a high risk of causing permanent damage to the fetus that they should not be used in pregnancy or when there is a possibility of pregnancy.

Not assigned

Controlled studies in women fail to demonstrate a risk to the fetus in the first trimester (and there is no evidence of a risk in later trimesters) and the possibility of fetal harm appears remote.

Either animal reproduction studies have not demonstrated a fetal risk but there are no controlled studies in pregnant women or animal reproduction studies have shown an adverse effect lother than a decrease in fertility) that was not confirmed in controlled studies in women in the first trimester land there is no evidence of a risk in later trimesters).

Either studies in animals have revealed adverse effects on the fetus (teratogenic or embryocidal or other) and there are no controlled studies in women or studies in women and animals are not available. Drugs should be given only if the potential benefit justifies the potential risk to the fetus.

There is positive evidence of human fetal risk, but the benefits from use in pregnant women may be acceptable despite the risk le.g. if the drug is needed in a life-threatening situation or for a serious disease for which safer drugs cannot be used or are ineffective).

Studies in animals or human beings have demonstrated fetal abnormalities or there is evidence of fetal risk based on human experience or both, and the risk of the use of the drug in pregnant women clearly outweighs any possible benefit. The drug is contraindicated in women who are or may become pregnant.

Not assigned.

- Compatible. In general, this option is considered the drug of first choice, which should be tolerated during pregnancy and/or breastfeeding, as there is sufficient anecdotal evidence through use during human pregnancies that the embryo/fetal risk is very low or nonexistent.

- Probably safe. In general, there is limited trial experience during human pregnancy (or during breastfeeding), but the characteristics of the drug and/or drugs in the same class suggest low risk.

- Possibly safe. This drug is considered for second-line use, if better-tested treatment options fail. Direct maternal benefit is thought likely to outweigh potential risk during pregnancy and/or breastfeeding, although exact risks are unknown.

- Breastfeeding. Please note that all listed refer to use in full-term, healthy, exclusively breastfed babies from mothers taking a listed drug at the standard recommended dose(s) and duration(s).

In all cases, the clinician should compare the benefits and risks of each medication.

In conclusion, the use of any drugs during pregnancy and lactation needs to balance the maternal risk of therapy versus no therapy and the fetal risk of uncontrolled maternal disease with the risk of therapy on the newborn. 
In women with asthma, inhaled medications have been used for many years without documentation of adverse effects on the fetus. In contrast, the effect of undertreated asthma resulting in a severe exacerbation with maternal hypoxia is well described to have adverse effects on the fetus.

Monoclonal antibodies are not likely to cross the placenta in sufficient quantities to cause fetal harm and should be continued during pregnancy if required for asthma control in the mother.

For women with bronchiectasis and CF, routine therapy with inhaled bronchodilators, corticosteroids antibiotics and mucolytics should continue to maintain maternal stability throughout pregnancy. Any risks associated with systemic antibiotics vary depending on the agent and selection should be based on clinical grounds for the mother balanced with risk to the fetus.

TABLE 2 Bronchodilators [23-30]

\begin{tabular}{|c|c|c|c|c|c|}
\hline SABAs & Pre/T1 & T2/T3 & Labour & Breastfeeding & Observations/considerations \\
\hline Salbutamol (A) [-] & \multicolumn{4}{|c|}{ Compatible } & \multirow[b]{2}{*}{$\begin{array}{l}\text { SABAs unlikely to cause structural anomalies } \\
\text { as observed risk in clinical studies and clinical } \\
\text { use is similar to that of the general population. } \\
\text { Systemic administration may cause } \\
\text { cardiovascular and metabolic adverse effects } \\
\text { including maternal and fetal tachycardia, } \\
\text { maternal hyperglycaemia, and neonatal } \\
\text { hypoglycaemia. Systemic } \beta_{2} \text {-agonists may have } \\
\text { a tocolytic effect during delivery. SABAs } \\
\text { (salbutamol, terbutaline) are preferred over } \\
\text { compounds with longer action. Excessive use } \\
\text { should be avoided. }\end{array}$} \\
\hline Terbutaline (A) [C] & & & ly safe & & \\
\hline
\end{tabular}

\section{LABAs}

\begin{tabular}{|l|l|}
\hline & \\
Formoterol (B3) [-] & Probably safe \\
Salmeterol (B3) [C] & \\
& \\
\hline
\end{tabular}

\section{Ultra-LABAs}

\begin{tabular}{|l|l|}
\hline $\begin{array}{l}\text { Olodaterol (B3) [-] } \\
\text { Vilanterol (B3) [C] }\end{array}$ & Possibly safe \\
\hline
\end{tabular}

\section{LAMAs}

\begin{tabular}{|l|l|l|}
\hline & & \\
Tiotropium bromide (B1) [-] & Possibly safe & Compatible \\
\hline
\end{tabular}

\section{Methylxanthines}

\begin{tabular}{|l|l|}
\hline Theophylline (A) [C] & Compatible \\
\hline & \\
\hline
\end{tabular}

Limited human data and animal data suggest no risk or low risk. Salmeterol is preferred due to greater experience during pregnancy. However, if pre-pregnancy the woman was already controlling symptoms with another LABA (e.g. formoterol), it is acceptable to continue with the same drug during pregnancy.

No human data; animal data suggest low risk.

Drug names are the generic compound, followed by Therapeutic Goods Administration (TGA) and Food and Drug Administration [FDA] classifications (table 1). Pre: pre-conception; T1: first trimester; T2: second trimester; T3: third trimester; SABA: short-acting $\beta_{2}$-agonist; LABA: long-acting $\beta_{2}$-agonist; LAMA: long-acting muscarinic antagonist.

Minimal experience during human pregnancy or lactation. Animal studies show no evidence of teratogenic effects, but high doses result in fetal toxicity limpaired embryo/fetal viability and delayed maturation).

Used in the treatment of asthma during pregnancy with no evidence of teratogenic effects. Blood levels should be monitored. If treatment continues until end of pregnancy, uterine contractions may be inhibited. Neonates exposed during pregnancy (at term)

[31] or lactation should be observed for evidence of toxicity or withdrawal (tachycardia, irritability and vomiting). It is considered sensible that breastfeeding women nurse their infants just before ingesting their regular dose. 
TABLE 3 Corticosteroids and leukotriene receptor antagonists $[24,25,28,32,33]$

\begin{tabular}{|c|c|c|c|c|c|}
\hline ICSs & Pre/T1 & T2/T3 & Labour & Breastfeeding & Observations/considerations \\
\hline $\begin{array}{l}\text { Budesonide (A) [B] } \\
\text { Beclomethasone (B3) [-] } \\
\text { Fluticasone (B3) [-] } \\
\text { Triamcinolone (B3) [-] }\end{array}$ & \multicolumn{4}{|c|}{ Compatible } & \multirow{2}{*}{$\begin{array}{l}\text { At usual dose, ICSs have not been associated with } \\
\text { increased risk of major malformations, IUGR, } \\
\text { pre-term delivery or low birthweight. One study } \\
\text { showed }>1000 \mu \mathrm{g} \cdot \text { day }^{-1} \text { beclomethasone was } \\
\text { associated with a small risk of congenital } \\
\text { malformation [34]. Budesonide and beclomethasone } \\
\text { have more data during pregnancy so are preferred. } \\
\text { However, if pre-pregnancy a woman is already } \\
\text { controlled with another ICS, she can continue it } \\
\text { during pregnancy. No reports describing inhaled } \\
\text { ciclesonide or mometasone during pregnancy. Use } \\
\text { lowest dose necessary to maintain asthma control. }\end{array}$} \\
\hline $\begin{array}{l}\text { Ciclesonide (B3) [C] } \\
\text { Mometasone (B3) [-] }\end{array}$ & & & oly safe & & \\
\hline
\end{tabular}

\section{Nasal corticosteroids}

\begin{tabular}{|l|l|c|c|}
\hline $\begin{array}{l}\text { Budesonide (A) [B] } \\
\text { Ciclesonide (B3) [C] }\end{array}$ & Probably safe & $\begin{array}{c}\text { Most studies showed no significant increase in } \\
\text { congenital malformations or premature birth in } \\
\text { children of women treated with topical }\end{array}$ \\
$\begin{array}{l}\text { Fluticasone (B3) [-] } \\
\text { Mometasone (B3) [C] }\end{array}$ & $\begin{array}{c}\text { Compatible } \\
\text { corticosteroids during pregnancy. One published case } \\
\text { of IUGR following topical triamcinolone in the mother } \\
\text { [35]. Some studies suggest a relationship between } \\
\text { topical corticosteroids and IUGR [36]. }\end{array}$ \\
\hline
\end{tabular}

\section{Systemic corticosteroids}

\begin{tabular}{|c|c|c|}
\hline $\begin{array}{l}\text { Prednisolone }(A)[C] \\
\text { Prednisone }(A)[C] \\
\text { Hydrocortisone }(A)[C]\end{array}$ & Possibly safe & $\begin{array}{l}\text { Conflicting data: some studies showed no increase in } \\
\text { birth defects in humans [37], others showed that } \\
\text { their use, especially during T1, is associated with a } \\
\text { 3-fold risk for isolated cleft lip } \pm \text { cleft palate, as well } \\
\text { as increased risk of pre-term delivery, low } \\
\text { birthweight and pre-eclampsia [38-40]. However, the } \\
\text { major benefit of systemic corticosteroids in severe } \\
\text { asthma exceeds the possible fetal risk. Only } 10 \% \text { of } \\
\text { the maternal concentration of prednisone and } \\
\text { prednisolone is found in fetal blood. If higher dose } \\
\text { continues until birth, adrenal insufficiency in the } \\
\text { newborn must be considered. Substitution with } \\
\text { hydrocortisone may be necessary when parenteral } \\
\text { administration is needed. With prolonged treatment } \\
\text { at high maternal doses, it is advisable to delay } \\
\text { breastfeeding for } 3-4 \mathrm{~h} \text { after the dose to minimise } \\
\text { transfer to breast milk. }\end{array}$ \\
\hline Montelukast (B1) [B] & Probably safe & $\begin{array}{l}\text { Limited data suggest no significantly increased risk } \\
\text { of malformations [41, 42], but number of exposed } \\
\text { women insufficient to ensure safety for the fetus. } \\
\text { Cases of limb reduction defects have been reported } \\
\text { [22]. Use during pregnancy when conventional } \\
\text { medications fail to secure asthma control. No data } \\
\text { during breastfeeding, but excretion into breast milk } \\
\text { is very low [43]. }\end{array}$ \\
\hline
\end{tabular}

Drug names are the generic compound, followed by Therapeutic Goods Administration (TGA) and Food and Drug Administration [FDA] classifications (table 1). Pre: pre-conception; T1: first trimester; T2: second trimester; T3: third trimester; ICS: inhaled corticosteroid; IUGR: intra-uterine growth restriction. 
TABLE 4 Other agents

\begin{tabular}{|c|c|c|c|c|c|}
\hline $\begin{array}{l}\text { Antihistamines }\left(\mathrm{H}_{1}\right. \\
\text { antagonists) }\end{array}$ & Pre/T1 & $\mathrm{T} 2 / \mathrm{T} 3$ & Labour & Breastfeeding & Observations/considerations \\
\hline $\begin{array}{l}\text { Cetirizine (B2) [-] } \\
\text { Chlorpheniramine (A) [B] } \\
\text { Dexchlorpheniramine (A) [B] } \\
\text { Loratadine (B1) [-] }\end{array}$ & \multicolumn{2}{|c|}{ Compatible } & \multicolumn{2}{|c|}{ Probably safe } & $\begin{array}{l}\text { Although several studies have reported } \\
\text { associations between specific } \mathrm{H}_{1} \text {-antihistamines in } \\
\text { early pregnancy and certain birth defects [44], in } \\
\text { general } \mathrm{H}_{1} \text {-antihistamines have not been linked to } \\
\text { increased risk of congenital anomalies [45-51]. } \\
\text { Antihistamine use during last } 2 \text { weeks of } \\
\text { pregnancy associated with retrolental fibroplasia in } \\
\text { premature infants in one study [52], although } \\
\text { these findings have not been corroborated. } \\
\text { Loratadine or cetirizine should be preferred as } \\
\text { they have been most used. Antihistamines may, in } \\
\text { theory, reduce milk production [23]. }\end{array}$ \\
\hline
\end{tabular}

Drug names are the generic compound, followed by Therapeutic Goods Administration (TGA) and Food and Drug Administration [FDA] classifications. Pre: pre-conception; T1: first trimester; T2: second trimester; T3: third trimester.

TABLE 5 Cystic fibrosis (CF) and bronchiectasis

\begin{tabular}{|l|c|c|c|c|}
\cline { 2 - 4 } \multicolumn{1}{c|}{ Mucolytics: inhaled } & Pre/T1 & T2/T3 & Labour & Breastfeeding \\
\hline $\begin{array}{l}\text { Hypertonic saline (-) [-] } \\
\text { Mannitol (B2) [C] } \\
\text { Dornase alfa (B1) [-] }\end{array}$ & \multicolumn{3}{|c|}{ Compatible } & Limited systemic absorption, widely used. \\
\hline
\end{tabular}


TABLE 5 Continued

\begin{tabular}{|c|c|c|c|c|c|}
\hline CFTR modulators & Pre/T1 & T2/T3 & Labour & Breastfeeding & Observations/considerations \\
\hline $\begin{array}{l}\text { Ivacaftor (B3) [-] } \\
\text { Lumacaftor and ivacaftor } \\
\text { (B3) [-] } \\
\text { Tezacaftor and ivacaftor } \\
\text { (B3) [-] } \\
\text { Elexacaftor and } \\
\text { tezacaftor and } \\
\text { ivacaftor (B3) [-] }\end{array}$ & \multicolumn{4}{|c|}{ Probably safe } & $\begin{array}{l}\text { Limited data in humans [56-58]. No evidence of } \\
\text { toxicity in animals at usual doses. Modulators are } \\
\text { present in breast milk, although potential effects on } \\
\text { the fetus are unknown. Maternal benefit may } \\
\text { outweigh potential risk during pregnancy and/or } \\
\text { breastfeeding, although exact risks are unknown. }\end{array}$ \\
\hline \multicolumn{6}{|l|}{ Antibiotics: inhaled } \\
\hline Tobramycin (D) [-] & \multicolumn{4}{|c|}{ Compatible } & Tobramycin (systemically) is category "D" and \\
\hline $\begin{array}{l}\text { Colistimethate sodium } \\
\text { (B2) [C] } \\
\text { Aztreonam (B1) [B] }\end{array}$ & \multicolumn{3}{|c|}{ Probably safe } & Compatible & $\begin{array}{c}\text { route has minimal absorption, it is considered to } \\
\text { have minimal risk. If required for clinical stability, } \\
\text { may continue during pregnancy. Minimise breast skin } \\
\text { exposure during inhalation. }\end{array}$ \\
\hline
\end{tabular}

\section{Antibiotics: oral}

Note during breastfeeding: most systemic antibiotics will be present in breast milk, so could cause falsely negative cultures in febrile infants or produce gastroenteritis due to alteration of intestinal flora.

\begin{tabular}{|c|c|c|c|}
\hline $\begin{array}{l}\text { Amoxicillin }(A)[B] \\
\text { Amoxicillin+clavulanic } \\
\quad \text { acid (B1) [B] }\end{array}$ & Compatible & & $\begin{array}{c}\text { Concern that exposure to these antibiotics during } \\
\text { organogenesis may be associated with oral clefts } \\
\text { (risk very low) [59]. Amoxicillin+clavulanic acid not } \\
\text { recommended in women at risk of pre-term delivery } \\
\text { (very low risk of necrotising enterocolitis in the fetus) } \\
\text { [60]. }\end{array}$ \\
\hline Azithromycin (B1) [B] & \multicolumn{2}{|l|}{ Probably safe } & $\begin{array}{l}\text { An epidemiological study suggests risk (very low) of } \\
\text { hypertrophic pyloric stenosis in infants exposed to } \\
\text { macrolides during first } 13 \text { days of breastfeeding (not } \\
\text { after } 2 \text { weeks) [61]. }\end{array}$ \\
\hline Cefuroxime (B1) [B] & \multicolumn{2}{|l|}{ Compatible } & $\begin{array}{l}\text { Human data indicate that cefuroxime land other } \\
\text { cephalosporins) not teratogenic at usual therapeutic } \\
\text { doses. }\end{array}$ \\
\hline Ciprofloxacin (B3) [C] & \multicolumn{2}{|l|}{ Possibly safe } & $\begin{array}{c}\text { In general, most clinicians try to avoid during } \\
\text { pregnancy and lactation. In animal studies } \\
\text { fluoroquinolones may be associated with fetal } \\
\text { cartilage damage, but human data suggest low risk } \\
\text { [62]. If a fluoroquinolone is indicated, ciprofloxacin } \\
\text { should be chosen. }\end{array}$ \\
\hline $\begin{array}{l}\text { Co-trimoxazole } \\
\text { (sulfamethoxazole } \\
\quad+\text { trimethoprim) (C) [-] }\end{array}$ & Avoid & Possibly safe & $\begin{array}{l}\text { In general, most clinicians try to avoid during } \\
\text { pregnancy. Trimethoprim may interfere with folic } \\
\text { acid metabolism (dihydrofolate reductase inhibitor] } \\
\text { [22]. One report noted an increased risk (very low) of } \\
\text { neural tube defects and other malformations [63], } \\
\text { which was not confirmed by others }[64,65] \text {. } \\
\text { Sulfonamide use associated with hyperbilirubinaemia } \\
\text { of the neonate and use at delivery associated with } \\
\text { fetal haemolytic anaemia [24]. Avoid during T1 and } \\
\text { T3 and at delivery. If necessary, folic acid } \\
\mathbf{5} \text { mg.day }{ }^{-1} \text { supplementation is generally used in } \\
\text { women treated with trimethoprim during T1. } \\
\text { Compatible with breastfeeding in healthy term } \\
\text { babies; avoid in babies who are glucose-6-phosphate } \\
\text { dehydrogenase deficient, jaundiced or premature. }\end{array}$ \\
\hline
\end{tabular}


TABLE 5 Continued

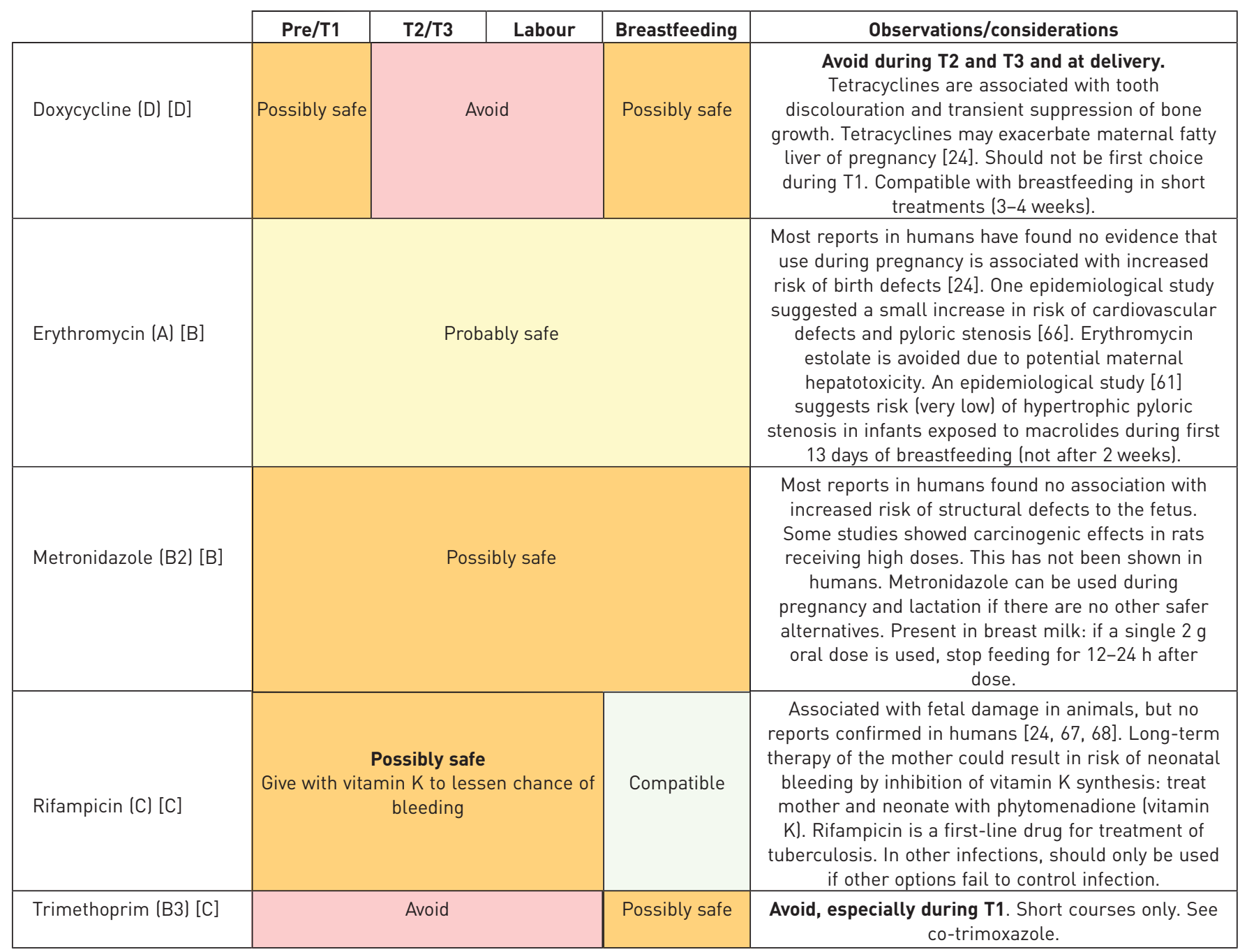

Antibiotics: i.v.

\begin{tabular}{|c|c|c|c|c|}
\hline Amoxicillin (A) [B] & \multicolumn{3}{|c|}{ See oral amoxicillin } & \\
\hline $\begin{array}{l}\text { Aminoglycosides } \\
\text { (gentamicin, } \\
\text { tobramycin) (D) [D] }\end{array}$ & $\begin{array}{c}\text { AVOID If possible } \\
\text { Streptomycin associated } \\
\text { with eighth cranial nerve } \\
\text { damage in the fetus } \\
\text { (non-CF case) }\end{array}$ & Possibly safe & Compatible & $\begin{array}{l}\text { Eighth cranial nerve toxicity in the fetus described } \\
\text { following exposure to other aminoglycosides } \\
\text { (kanamycin, streptomycin) [24, 69], but no reports } \\
\text { with tobramycin or gentamicin. Unconfirmed } \\
\text { theoretical risk of nephrotoxicity. In general, used } \\
\text { only as second- or third-line treatment in mothers } \\
\text { with severe infection when other antibiotics failed. } \\
\text { Monitor levels. Once-daily dosing preferred. If } \\
\text { treatment prolonged, renal function should be } \\
\text { monitored in the neonate and an auditory test } \\
\text { performed. Switch to inhaled where possible. } \\
\text { Present in breast milk in small amount. After i.v. } \\
\text { dose, avoid breastfeeding for } 2 \mathrm{~h} \text { following injection } \\
\text { when tobramycin in maximal concentration. Low oral } \\
\text { bioavailability overall, but unknown in premature } \\
\text { infants and neonates in first weeks of life. }\end{array}$ \\
\hline Ceftazidime (B1) [B] & \multicolumn{3}{|c|}{ Compatible } & $\begin{array}{l}\text { Most studies found that cephalosporin antibiotics in } \\
\text { general are safe to use in pregnancy. }\end{array}$ \\
\hline Meropenem (B2) [B] & Possibly safe & \multicolumn{2}{|c|}{ Probably safe } & $\begin{array}{c}\text { No fetal damage in animals. In humans, case reports } \\
\text { in T2 and T3 suggest no increase in risk. No reports } \\
\text { in T1. Low presence in breast milk, but no human } \\
\text { data. }\end{array}$ \\
\hline
\end{tabular}


TABLE 5 Continued

\begin{tabular}{|c|c|c|c|c|c|}
\hline & Pre/T1 & $\mathrm{T} 2 / \mathrm{T} 3$ & Labour & Breastfeeding & Observations/considerations \\
\hline $\begin{array}{l}\text { Piperacillin/tazobactam } \\
\text { (B1) [B] }\end{array}$ & \multicolumn{4}{|c|}{ Compatible } & $\begin{array}{c}\text { Experience limited, but all penicillins considered low } \\
\text { risk in pregnancy. Present in breast milk. Low oral } \\
\text { bioavailability, although in premature infants and } \\
\text { neonates there may be increased intestinal } \\
\text { absorption. }\end{array}$ \\
\hline Vancomycin (B2) [-] & Probably safe & & Compati & & $\begin{array}{c}\text { No teratogenic effects in animal studies. In human, } \\
\text { no cases of congenital defects have been located } \\
\text { [70], but experience during T1 limited. Present in } \\
\text { breast milk in nonsignificant amounts and low oral } \\
\text { bioavailability. }\end{array}$ \\
\hline
\end{tabular}

\section{Antifungals}

\begin{tabular}{|c|c|c|c|c|}
\hline Amphotericin (B3) [B] & \multicolumn{3}{|c|}{ Probably safe } & $\begin{array}{l}\text { Experience limited: small series on use of liposomal } \\
\text { amphotericin B during pregnancy did not find } \\
\text { adverse fetal outcomes [71]. No information on } \\
\text { breast excretion of amphotericin B. Little or no oral } \\
\text { absorption by fetus expected. Oral/topical use } \\
\text { acceptable in pregnancy and lactation. }\end{array}$ \\
\hline Fluconazole (D) [D] & Avoid & Possibly safe & Compatible & $\begin{array}{c}\text { In humans, data are limited; doses } \geqslant 400 \mathrm{mg} \cdot \text { day }^{-1} \\
\text { during } \mathrm{T} 1 \text { associated with malformations } \\
\text { (craniosynostosis, dysmorphic facies and others) [72]. } \\
\text { Most clinicians reserve this agent for } \\
\text { life-threatening infections. Single low doses } \\
(150 \mathrm{mg} \text { ) not associated with increase in congenital } \\
\text { malformations. Possible link between oral } \\
\text { fluconazole ( }>150 \mathrm{mg}^{-} \cdot \mathrm{day}^{-1} \text { ) and miscarriage [73]. } \\
\text { Present in breast milk, but less than neonatal } \\
\text { dosage. Problems not seen in breastfed infants from } \\
\text { mothers treated with oral fluconazole. }\end{array}$ \\
\hline Nystatin (A) [C] & \multicolumn{3}{|c|}{ Compatible } & $\begin{array}{l}\text { Poorly absorbed. Oral and local use acceptable in } \\
\text { pregnancy and lactation [74]. Any excess cream } \\
\text { should be removed from the nipples before nursing. }\end{array}$ \\
\hline Posaconazole (B3) [C] & \multicolumn{3}{|c|}{ Avoid } & $\begin{array}{l}\text { Animal data showed an increase in malformations in } \\
\text { the offspring [74]. No published human data. Use } \\
\text { should be considered only in life-threatening cases } \\
\text { after completion of } T 1 \text {, if no safer alternative. } \\
\text { Pharmacokinetic studies suggest drug will be } \\
\text { excreted in breast milk. No published human data in } \\
\text { nursing infants, but severe adult toxicity reported } \\
\text { (hepatotoxicity and others). }\end{array}$ \\
\hline
\end{tabular}


TABLE 5 Continued

\begin{tabular}{|c|c|c|c|c|c|}
\hline Pancreatic enzymes & Pre/T1 & $\mathrm{T} 2 / \mathrm{T} 3$ & Labour & Breastfeeding & Observations/considerations \\
\hline Pancrealipase (-) [C] & \multicolumn{4}{|c|}{ Compatible } & $\begin{array}{l}\text { Creon is a combination of porcine-derived lipases, } \\
\text { proteases, and amylases. No detailed studies in } \\
\text { animals or humans, but pancreatic enzymes are } \\
\text { widely used during pregnancy in CF mothers. }\end{array}$ \\
\hline
\end{tabular}

Vitamins [76]

Most vitamins (except Vitamin A and nicotinic acid/nicotinamide) are exempted from pregnancy listings when given within the RDAs.

\begin{tabular}{|c|c|c|}
\hline $\begin{array}{l}\text { Vitamin } A(D)[R D A=D, \\
\text { above } R D A=X]\end{array}$ & Probably safe & $\begin{array}{c}\text { Numerous reports showing no adverse effects during } \\
\text { pregnancy or breastfeeding at doses } \\
<10000 \mathrm{IU} \cdot \text { day }^{-1} \text {. High doses ( } \geqslant 25000 \mathrm{IU} \cdot \text { day }^{-1} \text { ) } \\
\text { should be considered potentially teratogenic } \\
\text { (craniofacial, central nervous system, cardiac and } \\
\text { other malformations involved). }\end{array}$ \\
\hline $\begin{array}{l}\text { Vitamin } B(-) \\
\quad[R D A=\text { unlisted, } \\
\text { above RDA=C] } \\
\text { Vitamin } C(-)[R D A=A, \\
\text { above RDA=C] } \\
\text { Vitamin D (-) } \\
\quad \text { RDA=unlisted, } \\
\text { above RDA=D] } \\
\text { Vitamin } E(-)[R D A=A, \\
\text { above RDA=C] } \\
\text { Vitamin } \mathrm{K}(-)[C]\end{array}$ & Compatible within RDAs & $\begin{array}{c}\text { No clinical data suggesting teratogenicity with } \\
\text { vitamin B1 (thiamine), B2 (riboflavin), B3 } \\
\text { (nicotinamide), B6 (pyridoxine), B12 } \\
\text { (cyanocobalamin), C (ascorbic acid), D (calciferol), } \\
\text { E (tocopherol) or K (phytomenadione) at usual doses. } \\
\text { Isolated cases of adverse effects reported in } \\
\text { neonates exposed to high doses of some vitamins } \\
\text { during pregnancy (B6: neonatal convulsions; C: } \\
\text { infantile scurvy; D: transient hypercalcaemia; K: } \\
\text { increased bilirubin). }\end{array}$ \\
\hline
\end{tabular}

\section{Gastrointestinal drugs}

\begin{tabular}{|c|c|c|c|}
\hline Antacids (A) [B] & \multicolumn{2}{|l|}{ Compatible } & $\begin{array}{c}\text { Most commercial preparations contain salts of } \\
\text { magnesium, calcium or aluminium. Fixed } \\
\text { combinations of aluminium and magnesium salts or } \\
\text { combination drugs are preferred, within } \\
\text { recommended doses. }\end{array}$ \\
\hline Ranitidine (B1) [B] & \multicolumn{2}{|l|}{ Compatible } & $\begin{array}{l}\text { Extensive experience available for the } \mathrm{H}_{2} \text { receptor } \\
\text { antagonists [77, 78]. Ranitidine is the best } \\
\text { investigated medication and should be preferred. }\end{array}$ \\
\hline $\begin{array}{l}\text { Rabeprazole (B1) [-] } \\
\text { Omeprazole (B3) [-] } \\
\text { Pantoprazole (B3) [-] } \\
\text { Esomeprazole (B3) [-] }\end{array}$ & \multicolumn{2}{|l|}{ Compatible } & $\begin{array}{l}\text { Large studies and meta-analysis [79] show no } \\
\text { evidence of adverse fetal effects. Omeprazole is the } \\
\text { best investigated medication so should be preferred } \\
\text { during pregnancy and lactation. However, in one } \\
\text { study a small cluster of cardiac anomalies was } \\
\text { observed after exposure to omeprazole [80], and } \\
\text { another study [81] identified an association between } \\
\text { use of proton pump inhibitors and hypospadias. }\end{array}$ \\
\hline $\begin{array}{l}\text { Other antiulcer: } \\
\quad \text { misoprostol }(X)[X]\end{array}$ & Avoid & Possibly safe & $\begin{array}{l}\text { Use during early pregnancy has been associated with } \\
\text { miscarriage and with congenital malformations in } \\
\text { surviving infants: palsies of the sixth and other } \\
\text { cranial nerves (Moebius syndrome), arthrogryposes } \\
\text { and others [24, 82]. Low levels in breast milk. } \\
\text { Monitor possible diarrhoea in the infant. }\end{array}$ \\
\hline
\end{tabular}

Drug names are the generic compound, followed by Therapeutic Goods Administration (TGA) and Food and Drug Administration [FDA] classifications (table 1). Pre: pre-conception; T1: first trimester; T2: second trimester; T3: third trimester; CFTR: CF transmembrane conductance regulator; RDA: recommended daily allowance.

\section{Pregnancy in women with asthma}

Pregnancy occurs commonly in women with asthma [83, 84], although some studies have noted a reduced ability to conceive $[6,7]$. Control of asthma triggers and comorbidities is recommended during pregnancy, including rhinitis [85], obesity [86] snoring and sleep disordered breathing [87], cigarette smoking [88], and viral infection [89]. Vaccination against influenza is recommended. Self-management education for 
asthma is also recommended, with improvements in skills and knowledge following education in pregnant women with asthma $[90,91]$.

\section{Natural history of pregnancy in women with asthma}

Asthma severity can change during pregnancy [92], with a later retrospective cohort of 1087 pregnancies showing $36 \%$ had improved asthma symptoms, $41 \%$ had unchanged symptoms and $23 \%$ had worsened symptoms during pregnancy [93]. Previous data suggested that during pregnancy asthma was unchanged in $33 \%$ and asthma was improved in $28 \%$ [94]. This has led to the concept that "one-third improve, one-third are unchanged and one-third experience increased asthma symptoms" [93, 95, 96]. In a recent study of 92 women, the proportion who deteriorated was smaller than this one-third hypothesis [97]. Prospective studies have shown a higher frequency of asthma exacerbations among those with more severe underlying disease. In general, the first trimester and the last month of pregnancy are relatively free of exacerbations. During the second and third trimesters increased asthma symptoms and need for medications is common $[96,98]$.

The change during pregnancy might be related to specific phenotypes, such as allergic or eosinophilic phenotypes, with rhinitis as an indicator of atopy associated with worsening asthma during pregnancy [85]. Asthma exacerbations in overweight or obese women during pregnancy are twice as frequent as in healthy weight women with asthma [86].

\section{Miscarriage, premature delivery and other obstetric complications associated with asthma}

International guidelines on the management of asthma during pregnancy are consistent in their main recommendations $[99,100]$. Most recommend monthly monitoring of symptoms due to the unpredictable course of asthma during pregnancy, which should include both obstetric care providers and a multidisciplinary respiratory team. A qualitative study reported that Australian midwives lacked confidence and certainty about their role in asthma management during pregnancy [101]. Barriers to midwife involvement included a lack of knowledge about asthma during pregnancy, lack of time and a lack of referral pathways to asthma specialists [101].

Maternal asthma is associated with reduced fetal growth (low birthweight) due to a combination of pre-term delivery and intra-uterine growth restriction (small for dates). Following pregnancies with a moderate-tosevere asthma exacerbation, there is an increased risk of pre-term birth, low birthweight [102, 103] and small for gestational age [104]. A meta-analysis of 13 studies found a $46 \%$ increased risk of low birthweight compared with women without asthma [102]. Maternal asthma is associated with increased risks of pre-eclampsia [102], gestational diabetes [105], caesarean section [105], perinatal mortality (driven by neonatal death) [27] and neonatal hospitalisation at birth [27].

Active asthma management during pregnancy was found to lessen the increased risk of pre-term birth [102], neonatal hospitalisation [27] and gestational diabetes [105]. Exhaled nitric oxide fraction-guided management was reported to reduce asthma exacerbations [83], reduce neonatal hospitalisation [83], reduce infant bronchiolitis [106], and reduce the later development of childhood wheeze and asthma [106]. There is a small but statistically significant increased risk of congenital malformations (relative risk 1.11, 95\% CI 1.02-1.21) in women with asthma [27]. This increased risk does not appear to be associated with maintenance asthma medication, with large studies demonstrating the relative safety of ICS use in relation to congenital malformations [107, 108].

\section{Exercise, nutrition, asthma and pregnancy}

At present the recommendations for pregnant women with asthma are based on those for the general population [109]. Maternal exercise during pregnancy is beneficial for reducing the incidence of low fetal birthweight and is likely to be important for pregnancy in overweight or obese women [110].

Most pregnant women with asthma have vitamin D levels $<75 \mathrm{nmol} \cdot \mathrm{L}^{-1}$ throughout gestation, which are associated with a greater risk of adverse respiratory outcomes in the infants. Those women with lower levels of vitamin D are at higher risk of having infants who later develop childhood asthma [111]. Vitamin $\mathrm{D}$ exposure during fetal development influences the immune system of the neonate, which can contribute to protection from asthma-related outcomes in early life [112].

\section{Breastfeeding}

A systematic review of observational studies on breastfeeding shows that breastfeeding is effective at preventing allergy in infants, with the most pronounced effect in infants at higher risk of allergy, when breastfed for at least 4 months [113]. However, longer follow-up studies of older children and adults found no protective effect against atopy and asthma, suggesting that the protective effect of breastfeeding delays rather than prevents development of atopy and asthma [114]. 


\section{Summary}

Most cohort studies demonstrate that asthma is associated with adverse outcomes during pregnancy that are related to poor asthma control, especially acute exacerbations. Some of these adverse outcomes can be reduced by good asthma management. More randomised controlled trials of pregnant women with asthma will strengthen the recommendations [115].

\section{Pregnancy in women with CF}

One of the fundamental components of care is that all people with CF should be managed in a multidisciplinary clinic on a long-term basis. Fertility and pregnancy issues should be discussed at an appropriate time before pregnancy is contemplated to optimise follow-up and treatment $[17,116]$. As noted in the earlier section on reproduction and conception issues, the prevalence of subfertility among women with CF (35\%) is higher than in the general population (5-15\%). Older age and pancreatic insufficiency are associated with subfertility in women with CF [14]. The partner should be offered testing for CFTR mutations during the pre-conception workup. In general, those women with good respiratory and nutritional status can achieve conception and maintain pregnancy to term.

\section{Natural history of pregnancy in women with CF}

While the older literature outlines increased risks of pregnancy-associated complications and miscarriages, this may have reflected worse nutrition and lung function in previous series. Since the initial case report in 1960 of a pregnancy in a woman with CF [117] with delivery of a viable fetus, it was soon noted that maintenance of the mother's health pre- and post-delivery was crucial. During the 1970s, CoHEN et al. [118] collected data from 129 pregnancies among 100 women with a mean age of 20.7 years. Medical abortion was undertaken in 19\% with an additional 5\% having a spontaneous miscarriage. Maternal mortality in this original series was $12 \%$ within 6 months of delivery and $18 \%$ within 2 years. More recent studies have shown similar levels of medical abortions, but better maternal survival [119].

Case series of women with CF have shown increased risk of miscarriages [120], both early and mid-pregnancy, with the chance of live birth reduced in mothers with worse lung function. For that reason, some authors have suggested that a pre-pregnancy forced expiratory volume in $1 \mathrm{~s}\left(\mathrm{FEV}_{1}\right)>60 \%$ predicted should be present before pregnancy is undertaken [121], while others suggest a cut-off of $\mathrm{FEV}_{1}>70 \%$ predicted [122] and others have shown that those women with $\mathrm{CF}$ with an $\mathrm{FEV}_{1}>80 \%$ predicted have better outcomes [123]. Clearly risks are lower in those with better lung function pre-pregnancy, but there have been successful pregnancies in women with $\mathrm{FEV}_{1}<40 \%$ predicted $[119,124]$. As maternal and fetal risks are increased in those with lower pre-conception $\mathrm{FEV}_{1}$, pregnancy in a woman with $\mathrm{CF}$ and advanced lung disease can be difficult to manage.

Pre-existing CFRD is an important consideration during pregnancy. A recent analysis of the French CF Registry compared outcomes of pregnancy in women with CF with and without pre-gestational diabetes, noting that women with CFRD were older at the time of first pregnancy ( 29 versus 26 years; $\mathrm{p}=0.05$ ) and had worse lung function ( $\mathrm{FEV}_{1} 50 \%$ versus $67 \%$ predicted; $\mathrm{p}=0.03$ ) [15]. There was an increased rate of caesarean section in diabetic women compared with nondiabetic women ( $48 \%$ versus $21 \%$; $\mathrm{p}=0.005$ ) [15]. However, there was no significant impact on fetal growth or pre-term delivery and there was no difference in long-term outcomes in the two groups [15].

\section{Risks to the fetus}

While there has long been an increase in the risk of miscarriages in women with CF having pregnancies, earlier studies did not demonstrate any difference in congenital anomalies [17, 116]. However, a recent population study of pregnancies in California between 2005 and 2008 compared the outcomes of pregnancies from mothers with CF versus those of the general population. They reported a significant increased risk of congenital anomalies $(14.3 \%$ versus $6.4 \%$; $\mathrm{p}<0.005)$ [120].

\section{Long-term maternal outcomes}

Overall, the US Cystic Fibrosis Foundation National Patient Registry demonstrated that women with CF who reported a pregnancy showed no reduction in overall survival compared with age-matched women with CF who did not report a pregnancy [124]. Data from the Epidemiologic Study of Cystic Fibrosis (ESCF) showed that pregnancy and motherhood were not associated with accelerated loss of lung function, but were linked to more pulmonary exacerbations and increased clinic visits [125]. However, a single-centre review has shown that following pregnancy, of 15 women with $\mathrm{FEV}_{1}<50 \%$ predicted, seven died within 8 years of delivery [126].

There are multiple cases of women colonised with Burkholderia species, in particular the Burkholderia cepacia complex, who have had poor outcomes following pregnancy [127, 128]. TANSER et al. [129] noted a 
particularly difficult combination of poor lung function $\left(\mathrm{FEV}_{1}<50 \%\right.$ predicted) with B. cepacia colonisation where maternal mortality was high. At present, there is little information concerning pregnancy in women colonised with mycobacterial species, but many of the drugs used to treat these organisms are not recommended for use during pregnancy.

\section{CFTR modulators}

With the recent introduction of ivacaftor and lumacaftor as CFTR modulators, there have been a number of reports of these agents being used during pregnancy and during breastfeeding [56, 58, 130, 131]. To date, there have been no reports of abnormalities associated with these agents, but the relative benefits of remaining on CFTR modulator therapy before, during and after pregnancy would need to be balanced against any theoretical risks.

\section{Suggestions for management during pregnancy}

Women with CF who are pregnant should be reviewed in a multidisciplinary CF clinic at least monthly for the first and second trimesters, increasing to every 2 weeks or more frequently as necessary. It is recommended that more frequent follow-up during pregnancy be undertaken in those with more severe disease. As many women with CF can develop gestational diabetes and require insulin, the European Cystic Fibrosis Society recommends that an OGTT should be performed pre-pregnancy and repeated at 20 weeks, and again at 28 weeks if necessary [17]. The US [18] and Australian guidelines [19] suggest an OGTT should be performed pre-pregnancy and at $12-16$ and $24-28$ weeks gestation in all women with CF.

\section{Nutritional considerations}

Women with CF are expected to gain an overall 10-12 kg during pregnancy, as would the general obstetric population [17]. Fat-soluble vitamins and other supplements should continue during pregnancy in order to maintain normal levels of all vitamins [17]. In addition to folate and iron supplements as recommended for all pregnant women, calorie supplements may also be required to provide sufficient energy intake to allow for normal weight gain during pregnancy.

\section{Increased intensity of maintenance treatments to maintain stability during pregnancy}

During pregnancy the ongoing routine care of the CF adult needs to be encouraged. As reflux increases during pregnancy [17], adjustments to physiotherapy regimens may be necessary. Many women change their daily routine to have more frequent smaller meals and time their physiotherapy before meals to minimise reflux. A high degree of individualisation is required as there are no studies confirming the "best option".

\section{Loss of lung function}

In general, it is expected that women with CF will transiently lose lung function to a similar level as other pregnant women. However, there are very few studies outlining the relative drop in lung function for women with CF with differing levels of lung function pre-conception. Many studies have compared pregnancy outcomes against pre-pregnancy lung function. In general, higher values of $\mathrm{FEV}_{1}$ pre-pregnancy are associated with better outcomes and complete return of lung function after pregnancy [123]. Importantly, long-term lung function in the group of women with CF who have had a pregnancy is similar to those who have not been pregnant [125].

\section{Physiotherapy issues: exercise, airway clearance and pelvic floor}

Regular airway clearance and exercise should be an established routine before pregnancy and maintained through pregnancy, with modification as necessary, including avoiding contact sports $[132,133]$. Although there are no trials comparing physiotherapy interventions in pregnant women with $\mathrm{CF}$, options include the active cycle of breathing technique, autogenic drainage, positive expiratory pressure (PEP) therapy, oscillating PEP and intrapulmonary percussive ventilation including the MetaNeb device [134]. Therapy may need to be adjusted as the fetus grows.

Upright sitting is often the most comfortable position for airway clearance during pregnancy, and instruction to maintain a neutral lumbar spine during airway clearance for optimal bladder control and prevention of back problems may be necessary [134]. Left and right side lying, horizontal or head up may be more effective positions in some women, but most clinicians avoid the supine horizontal position, especially during the second and third trimesters to minimise pressure from the gravid uterus on the inferior vena cava, which may decrease venous return and cardiac output.

The growing fetus results in upward pressure on the diaphragm and downward pressure on the pelvic floor. Particularly during the third trimester, increased stress on the pelvic floor may result in urinary 
leakage, especially during coughing. In most clinics, women with CF are taught effective pelvic floor strength and endurance exercises with referral to a physiotherapist experienced in this area.

\section{Post-transplant: is this a second chance?}

An important paper from GYI et al. [135] in 2006 outlined 10 CF lung transplant recipients who became pregnant. There were nine live births and one therapeutic abortion. Five of the nine births were premature. Four women died of rejection within 3 years of pregnancy. More recently, a retrospective review of pregnancies reported to the US National Transplant Registry detailed 30 pregnancies in 21 women post-transplant [136]. They described 18 live deliveries at an average gestation of 34 weeks, with a weight of $2.2 \mathrm{~kg}$. There were 11 complications including two neonatal deaths in the offspring and five of the 21 mothers died during follow-up. In summary, these studies have shown that pregnancy in lung transplant recipients is "feasible, but should still be regarded as a risky undertaking" [135].

\section{Summary}

In contrast to the literature concerning randomised trials of management of pregnancy in women with asthma, most studies in women with CF considering pregnancy are observational, without any prospective evaluation of any particular therapies. The increasing number of women with CF who have relatively preserved lung function and nutrition achieving adulthood means that there is an ever-growing number of women considering pregnancy. Management during pregnancy is generally optimised by cooperation of the CF multidisciplinary team in conjunction with the obstetric team and most established adult CF centres have close links with their local obstetric colleagues using "high-risk pregnancy clinics" to coordinate the complex management required.

\section{Pregnancy in women with bronchiectasis Natural history of pregnancy}

In contrast to other airways diseases, the natural history of pregnancy in women with bronchiectasis is much less documented. One of the early case series described three women with idiopathic bronchiectasis who successfully completed term pregnancies [137]. Women with primary ciliary dyskinesia are often subfertile, but not completely infertile, as there are case reports of natural pregnancies [138]. Women with bronchiectasis secondary to other diseases such as immunodeficiency will require consideration of both their primary underlying disease as well as their bronchiectasis when contemplating pregnancy.

\section{Miscarriage rates}

Although women with asthma have a slightly increased risk of miscarriage, the risks in women with bronchiectasis are at present unknown. Further studies are now necessary to document whether there is an increased risk of miscarriage in women with established lung disease and whether the different causes of bronchiectasis have different risks during pregnancy. Extrapolating from other airways diseases, it would be expected that all pregnancy-related problems would be increased, reflecting the lack of respiratory reserve dependent on lung function.

\section{Suggestions for follow-up}

As there is little literature available, management during pregnancy must be made on clinical acumen. Overall, it is expected that increased clinic visits would be necessary in the second and third trimesters as respiratory compromise from the growing fetus limits airway clearance.

\section{Exercise and nutrition}

Clinical experience suggests that exercise and nutritional requirements for optimisation of lung function during pregnancy would be similar to those of $\mathrm{CF}$, except with regard to pancreatic dysfunction. Maintenance of regular moderate intensity exercise and good nutrition throughout pregnancy would be recommended, in keeping with the general population [132].

\section{Physiotherapy}

Similar to the issues for women with CF, the growing fetus will impact on the respiratory system and pelvic floor. Optimal airway clearance should continue throughout pregnancy to prevent sputum retention. Modification to airway clearance techniques and physical exercise will be required as pregnancy progresses. No specific programmes for women with bronchiectasis are available in the literature, so most physiotherapists would tailor their therapy to reflect the management of women with CF who become pregnant. Management of the pelvic floor to prevent urinary leakage especially during airway clearance techniques and coughing will most likely require similar interventions as outlined in the section on pregnancy in women with $\mathrm{CF}$. 


\section{Management of birth in women with airways diseases \\ Introduction}

Labour is often divided into three stages. The first stage of labour involves the gradual shortening and dilatation of the cervix up to $10 \mathrm{~cm}$. This process may take up to $36 \mathrm{~h}$ in the primipara and is shorter in those who have previously had children. The second stage of labour involves the descent of the fetus through the birth canal and delivery, which may take between $30 \mathrm{~min}$ and $2 \mathrm{~h}$. The third stage of labour comprises the delivery of the placenta, which may take up to $1 \mathrm{~h}$ if not induced.

\section{Labour}

During labour, the resting hyperventilation of pregnancy increases further. This still exceeds the increased oxygen demand of labour and delivery, so most healthy women will not have hypoxia or hypercapnia. However, pain and anxiety can lead to rapid shallow breathing and a decrease in alveolar gas exchange. As expected, hypoxia, hypercapnia and respiratory acidosis occur more readily in women with more severe pulmonary disease [139].

There are no published studies specifically addressing intra-partum management in women with respiratory disease. Most applicable guidelines suggest evaluation prior to pregnancy or in early pregnancy, to develop a detailed and individualised management plan for birth, including place and mode of delivery, appropriate monitoring during delivery (e.g. arterial oxygen saturation measured by pulse oximetry), provision of necessary pulmonary interventions (e.g. inhalers for asthma, physiotherapy for CF and supplemental oxygen as required), and invasive and noninvasive monitoring during and after birth [17, 100]. Adequate pain relief during labour is a high priority for women with $\mathrm{CF}$ and other chronic suppurative lung diseases, with a normal vaginal delivery being highly desirable in order to minimise post-delivery complications [140].

\section{Obstetric considerations}

As noted in the section on pregnancy in women with asthma, some studies have shown an association between asthma and increased caesarean section rate [141-144], but this may be due to planned caesarean section or an increased rate of induction of labour rather than due to any direct effect of asthma. Moreover, there are no trials to address whether there is any clinical benefit of caesarean section versus vaginal birth in women with respiratory disease. Advantages of natural vaginal delivery include quicker recovery in those with bronchiectasis or $\mathrm{CF}$ and some studies suggested that children born by caesarean section in mothers with asthma may have an increased risk of subsequent asthma [145], while other studies did not [146].

Most guidelines suggest that the decision for caesarean section should be made for obstetric indications $[17,147]$. However, modification of the birth plan in women with significant airways disease may be required [2]. This may include elective delivery to ensure specialist staff are available, modifications to the second stage of labour to ensure the expulsive phase of labour is not prolonged, adequate analgesia and oxygen as required, and avoidance of general anaesthetic if possible. In women with CF, adequate maintenance of hydration, nutrition and blood glucose control also need to be considered [17].

The use of prostaglandin $\mathrm{E}_{2}$ for induction of labour or oxytocin (for augmentation of the second and third stages) has not been associated with worsening lung function or asthma exacerbation [148]. However, a recent case report outlined a woman with severe bronchiectasis $\left(\mathrm{FEV}_{1} 32 \%\right.$ predicted) who developed acute hypoxaemia when given oxytocin for uterine contraction [149]. As the hypoxaemia was resistant to supplemental oxygen it was suggested that the oxytocin had increased shunting through the damaged lung. We could find no studies to assess active versus physiological management of the third stage of labour in women with respiratory disease; however, the NICE guidelines advocate an active third stage of labour for women as it is associated with a lower risk of post-partum haemorrhage and/or blood transfusion [150]. As discussed in the following, several of the uterotonics used for post-partum haemorrhage have significant adverse effects on the respiratory system; ergotamine may cause bronchospasm, particularly in association with general anaesthesia [151], so oxytocin is the uterotonic of choice for the active third stage of labour.

\section{Anaesthetic considerations}

Pre-delivery evaluation and multidisciplinary planning is the cornerstone in managing pregnant women with respiratory disease. Adequate pain relief will reduce anxiety and maternal stress. Early epidural analgesia with local anaesthetics (with or without opioids) for labour pain is the preferred method. Lumbar epidural analgesia can be extended into safe and proper anaesthesia in the case of an emergency caesarean section, thereby avoiding the need for airway management. Systemic opioids can provide 
moderate pain relief, but will suppress cough, suppress ventilation and may induce bowel obstruction especially in women with CF. A cautiously titrated epidural for analgesia is generally preferred [152].

\section{Respiratory considerations}

Exacerbations of asthma are uncommon during labour [98]. It is generally accepted that usual asthma medications should be continued during childbirth [147]. Inhaled or parenteral $\beta$-agonists have been used as a tocolytic in women with threatened pre-term labour [153] or uterine hyperstimulation, but there is no published evidence that inhaled $\beta$-agonists used for asthma treatment affect the course of labour. In women receiving oral steroids $(7.5 \mathrm{mg}$ daily for at least 2 weeks) there is a potential risk of maternal hypothalamic-pituitary-adrenal axis suppression, which has led to the widespread practice of giving "stress dose" hydrocortisone intravenously during active labour and during caesarean section [147]. For women with more severe disease, assisted ventilation strategies may be considered with appropriate intensive care unit backup. In women with established bronchiectasis, positive end-expiratory pressure may assist by splinting open smaller airways to prevent dynamic airway closure and hence better mobilisation of secretions.

\section{Role of physiotherapy}

Pain, shortness of breath and low oxygen saturation during labour are reported in some healthy women during parturition. Women with chronic airways disease would be expected to experience these symptoms at an increased frequency or severity during labour, although this has not yet been documented. Oxygen therapy should be provided to maintain normal saturations as per standard care. Bronchodilator therapy and assistance with sputum clearance may be required by some women during labour.

\section{Summary}

There is little evidence at present to guide management decisions in the intra-partum period. Most disease-specific guidelines offer recommendations based on low-grade evidence or consensus opinion. Caesarean section appears to be more common in this population, likely for multifactorial reasons. Active management of the third stage of labour may be considered using oxytocin without ergotamine in women with lung disease.

\section{Post-partum considerations}

\section{Introduction}

The post-partum period is a particularly vulnerable time for the medically unwell woman, with risks of cardio-respiratory decompensation, infection, sepsis and haemorrhage. Guidelines advocate that the birth management plan includes the first few days post-partum, with recommendations on the location for post-delivery care in the maternity unit or respiratory/high dependency unit balancing the individual needs of the woman and her baby.

\section{Obstetric considerations}

Post-partum haemorrhage, defined as $\geqslant 500 \mathrm{~mL}$ of bleeding within $24 \mathrm{~h}$ of birth, occurs in $2.5-5 \%$ of women post-delivery. While observational studies have suggested that there is no increase in post-partum haemorrhage in women with lung disease, a meta-analysis showed that there were significant increases in both ante-partum and post-partum haemorrhage [105].

Prostaglandin $\mathrm{F}_{2 \mathrm{a}}$ used to treat post-partum haemorrhage due to uterine atony may cause bronchoconstriction [151]. Although not associated with clinical exacerbations [143], it is recommended not to be used in women with asthma [2]. Ergometrine may also cause bronchospasm particularly in association with general anaesthetics [151]. Women on long-term systemic corticosteroids have an increased risk of poor wound healing and infection, which is especially important after caesarean section in those with suppurative lung disease who require daily airway clearance to maintain health. As the risk of post-partum venous thromboembolic disease is increased in those with immobility [154], it is important that women are mobilised or thromboprophylaxis with low-molecular-weight heparin may need to be considered.

\section{Anaesthetic considerations}

Optimal post-partum analgesia allows early mobilisation with minimal side-effects. Pain should be assessed and managed in a multimodal way. The respiratory depressant effect of opioids and suppression of cough are particularly important in women with respiratory diseases. The level of care and monitoring post-partum should be considered in a multidisciplinary setting balancing both obstetric and airway risks for the mother with any risks for the newborn. 


\section{Respiratory considerations}

Some older studies have noted an increased risk of post-partum asthma exacerbation in women having caesarean sections [143], but this group was generally not taking ICSs. For CF and bronchiectasis, the outcomes are less well known.

\section{Physiotherapy in the postnatal period}

Physical support for the mother is important after birth to allow sufficient time to inhale medications, perform airway clearance therapy and exercise to prevent exacerbations. These factors are more important after caesarean section, especially in those with underlying airways disease (see previous sections).

\section{Breastfeeding issues}

Breastfeeding is universally advocated in international maternity guidelines. However, for some women with significant airways disease, nutritional, pharmacological and other factors need to be considered. Medications commonly used in women with airways disease and their evidence for use during breastfeeding are described in tables $2-5$.

It is generally accepted that the composition of salts and proteins in the breast milk from a woman with $\mathrm{CF}$ are within normal limits [155]. As breastfeeding increases maternal protein, calcium and overall caloric requirements by $\sim 500 \mathrm{kcal}^{-\mathrm{day}^{-1}}$, an individualised approach is necessary especially for women with CF. These concerns should be balanced with the beneficial effects of breastfeeding overall (see tables 2-5).

\section{Summary}

While there is little evidence to guide management decisions in the immediate post-partum period and most disease-specific guidelines offer recommendations based on low-grade evidence or consensus opinion, post-partum haemorrhage may be increased in women with asthma and medications used for the management of post-partum haemorrhage may affect the respiratory system. Close collaboration between the obstetric and respiratory teams is necessary to optimise management.

\section{Patients' views about family planning, pregnancy and parenthood}

The European Lung Foundation, in collaboration with patient volunteers, designed an online survey to better understand women's views about conception, pregnancy and childbirth when living with an airways disease. The survey was open to women from 26 countries with a variety of lung conditions, but this summary only examines the views of those with asthma $(n=162)$, CF $(n=154)$ and bronchiectasis $(n=15)$. Respondents included those who had never been pregnant $(n=132)$, those who were currently pregnant $(n=18)$ and those who had been pregnant in the past $(n=181)$.

Participants were asked to complete a questionnaire-based survey outlining how important they considered the impact of their lung condition on fertility, pregnancy and the ability to parent. Responses varied across conditions and between those who had been or were currently pregnant and those who had never been pregnant. Relatively few respondents with asthma (25\%) considered their asthma of importance for fertility, whereas many respondents with $\mathrm{CF}$ and bronchiectasis found their disease of importance for fertility (78\% and $73 \%$, respectively). For pregnancy itself, $54 \%$ of respondents with asthma rated their condition as important compared with $85 \%$ of respondents with CF and $63 \%$ of respondents with bronchiectasis. The ability to parent with their lung condition was considered important or very important for 32\% of respondents with asthma, $92 \%$ of respondents with CF and $73 \%$ of respondents with bronchiectasis. Across the three conditions, those who had never been pregnant described fertility, pregnancy and the ability to parent as more of a problem due to their condition. This may reflect some women who have chosen not to have children due to their condition and, in particular, those who were motivated to complete an online survey.

Furthermore, respondents were invited to add free-text answers relating to the following questions:

1) What support they would have found beneficial.

2) Further information they would have liked.

3) Whether their lung condition influenced their decision to have children.

4) Standards of care during their pregnancy.

\section{Asthma}

The decision to get pregnant was not influenced by having asthma and many women felt that it did not affect their pregnancy adversely. Some were very concerned about their asthma worsening during pregnancy or were worried about their ability to take care of their current offspring. Respondents were not confident that they could recognise the signs of asthma deterioration. Those women with a respiratory 
specialist valued having this input and many of those without a respiratory specialist would have liked to have seen one while pregnant. Many felt that primary care was not able to answer all questions about continuing medications and their effects on the offspring while pregnant and breastfeeding. Women accessed information from patient organisations and felt that asthma was often not adequately addressed during their pregnancy. Furthermore, options concerning birth and postnatal care were not adequately covered in all cases.

\section{Cystic fibrosis}

Women with CF are very aware of the difficulty in getting pregnant, the need for genetic testing and the impact of pregnancy on their health. Many respondents reported not getting pregnant due to fears of their child having CF and the impact on the health of the offspring. Some felt the risk of not being well enough to care for their child or potentially dying before their child was an adult was too big a chance to take. Some were worried that they would regret not trying to have children but felt conflicted due to these concerns. Many women reported that they could not afford fertility treatments, and some felt the length of time needed to get genetic tests and find a maternity unit that understands CF should be flagged with patients earlier. Some women felt surrogacy was their best chance of becoming a parent, although this is not available in all countries. Many women felt that having CF would be an issue for adoption. Many women felt that too much emphasis was placed on pregnancy and not enough priority was given to being a parent while living with CF. Women described the impact of having a child on their health, which was similar to the experience of the respondents with bronchiectasis described below.

Those who were or had been pregnant acknowledged that their pregnancy was not without worry, but that they were very motivated to have a child. Some reported having their children early due to concerns about their life expectancy. Several women stated that due to the impact of their first child on their health, they had chosen not to have another child. Women reported that they would appreciate networking with other mothers living with CF to discuss the practical issues of parenting. A recent online survey in Australia using closed-group moderated discussions showed that women with CF desired more information about childbearing, expressing concern about the safety of their CF medications during pregnancy [156].

\section{Bronchiectasis}

Overall, women reported that they did not give their condition much thought and were more focused on getting pregnant. However, some did report that they would not have more children due to the impact on their lungs. They described feeling "well looked after" with involvement and coordination between their respiratory and obstetrics teams. Some emphasised the impact as a parent with a chronic lung condition of having a small child who brings illnesses into the home. They felt that there should be more support about how to manage this issue. Women also related that the strain of caring for a newborn was very difficult given their condition and felt that further support for mothers with bronchiectasis was needed to mitigate these difficulties.

\section{Summary}

The patients' perspective concerning conception, pregnancy and the postnatal period differs markedly between the three conditions. Those with asthma and bronchiectasis often do not consider their condition when deciding whether to try to conceive, in contrast to the protracted decisions for those with CF. While respondents with asthma reported not having access to respiratory professionals during their pregnancy, those with bronchiectasis did not have this problem. For CF, the issue raised was often the difficulty finding obstetric specialists who had experience of dealing with pregnancy in women with CF and the length of time taken for genetic testing and fertility treatments. In general, women with chronic airways disease felt that they were not adequately prepared for the postnatal period and parenthood in general.

\section{Conclusions}

This statement outlines the current level of knowledge concerning the management of women with asthma, CF and bronchiectasis before, during and after pregnancy. In general, for pregnancy-related issues in women with airways diseases there are very few randomised controlled trials, so the evidence consists of cross-sectional surveys, case series and post hoc analysis of other trials. However, recent longitudinal cohort studies are starting to address issues of clinical management in women with asthma, reflecting difficulties for women with asthma to conceive and maintain lung function during pregnancy and parturition. For CF and bronchiectasis there are few trials in this important area, so the data relate to considered opinion. For women with bronchiectasis, conception is less an issue than the post-partum issue of maternal respiratory infections. In women with $\mathrm{CF}$, there are well-described conception difficulties together with the post-partum infection problem. 
Tables 2-5 on drugs and their risks provide a summary for both respiratory and obstetric teams to rapidly refer to data concerning multiple drugs in different situations, but for more detailed information concerning a particular medication, the appropriate governmental listing should be consulted.

Patients' perspectives reveal that better guidance and involvement of respiratory physicians would reduce some of the concerns of women with asthma during pregnancy, while the majority of women with $\mathrm{CF}$ preferred management by a dedicated multidisciplinary team.

Lastly, this Task Force has summarised issues concerning pregnancy in women with airways disease, but has not addressed the offspring of these pregnancies and the future risk of disease in these offspring.

\section{Recommendations for future research/questions \\ General issues}

1) What are the fertility issues for women with airways diseases and what biomarkers can be determined for reduced fertility?

2) What are the relative outcomes of pregnancy for women with different airways diseases?

3) What is the best way to optimise treatment in women with airways diseases?

4) What factors can predict risk of bad outcomes (miscarriage, stillbirth, poor obstetric outcomes)?

\section{Obstetric issues}

5) What pain relief options during birth are optimal for women with airways disease?

6) What uterotonics should be avoided in the third stage of labour?

7) What is the optimal dose of "stress dose" hydrocortisone to cover labour and caesarean section?

\section{Future issues}

8) What are the future risks to the mother with airways disease after pregnancy?

9) What are the future risks (if any) for children born to mothers with different airways diseases?

10) What is the best way to minimise these risks to the offspring?

Acknowledgements: The online survey was performed in collaboration with Marta Almagro, Annette Posthumus, Betty Frankemölle, Kenneth Hilliyard, Katie Gathercole, Hilde de Keyser, Jasmine Parkinson, Gill Hollis and Jill Pateman (European Lung Foundation). Respondents came from Andorra, Austria, Australia, Belgium, Canada, Columbia, Denmark, France, Germany, Greece, Hungary, Ireland, Lichtenstein, Luxemburg, Mexico, New Zealand, Norway, Poland, Portugal, Spain, Sweden, Switzerland, the Netherlands, United Arab Emirates, UK and USA.

Support statement: This work was supported by the European Respiratory Society (grant: TF-2016-23) and the Thoracic Society of Australia and New Zealand. Funding information for this article has been deposited with the Crossref Funder Registry.

Conflict of interest: P.G. Middleton has nothing to disclose. E.J. Gade has nothing to disclose. C. Aguilera has nothing to disclose. L. Mackillop reports grants from NIHR Oxford Biomedical Research Centre, personal fees from Sensyne Health plc, outside the submitted work; and was a member of the UK's NICE guideline committee for Intrapartum Care for High Risk Women which included a section on women with asthma. B.M. Button has nothing to disclose. C. Coleman is an employee of the European Lung Foundation. B. Johnson is an employee of the European Lung Foundation. C. Albrechtsen has nothing to disclose. F. Edenborough has nothing to disclose. D. Rigau acts a European Respiratory Society methodologist. P.G. Gibson reports grants and personal fees from AstraZeneca, GlaxoSmithKline, Novartis and Sanofi, outside the submitted work. V. Backer has nothing to disclose.

\section{References}

1 Edwards N, Middleton PG, Blyton DM, et al. Sleep disordered breathing and pregnancy. Thorax 2002; 57: 555-558.

2 National Institute for Health and Care Excellence. Intrapartum care for women with existing medical conditions or obstetric complications and their babies. NG121. 2019. www.nice.org.uk/guidance/ng121 Date last accessed: October 19, 2019.

3 Gade EJ, Thomsen SF, Lindenberg S, et al. Asthma affects time to pregnancy and fertility: a register-based twin study. Eur Respir J 2014; 43: 1077-1085.

4 Burgel PR, Bellis G, Olesen HV, et al. Future trends in cystic fibrosis demography in 34 European countries. Eur Respir J 2015; 46: 133-141.

5 Tata LJ, Hubbard RB, McKeever TM, et al. Fertility rates in women with asthma, eczema, and hay fever: a general population-based cohort study. Am J Epidemiol 2007; 165: 1023-1030.

6 Grzeskowiak LE, Smithers LG, Grieger JA, et al. Asthma treatment impacts time to pregnancy: evidence from the international SCOPE study. Eur Respir J 2018; 51: 1702035.

7 Gade EJ, Thomsen SF, Lindenberg S, et al. Fertility outcomes in asthma: a clinical study of 245 women with unexplained infertility. Eur Respir J 2016; 47: 1144-1151. 
Vejen Hansen A, Ali Z, Malchau SS, et al. Fertility treatment among women with asthma: a case-control study of 3689 women with live births. Eur Respir J 2019; 53: 1800597.

9 MacKenzie T, Gifford AH, Sabadosa KA, et al. Longevity of patients with cystic fibrosis in 2000 to 2010 and beyond: survival analysis of the Cystic Fibrosis Foundation patient registry. Ann Intern Med 2014; 161: 233-241.

10 de Souza DAS, Faucz FR, Pereira-Ferrari L, et al. Congenital bilateral absence of the vas deferens as an atypical form of cystic fibrosis: reproductive implications and genetic counseling. Andrology 2018; 6: 127-135.

11 Aittomaki K, Wennerholm UB, Bergh C, et al. Safety issues in assisted reproduction technology: should ICSI patients have genetic testing before treatment? A practical proposition to help patient information. Hum Reprod 2004; 19: 472-476.

12 Tizzano EF, Buchwald M. CFTR expression and organ damage in cystic fibrosis. Ann Intern Med 1995; 123: 305-308.

13 Edenborough FP. Women with cystic fibrosis and their potential for reproduction. Thorax 2001; 56: 649-655.

14 Shteinberg M, Lulu AB, Downey DG, et al. Failure to conceive in women with CF is associated with pancreatic insufficiency and advancing age. J Cyst Fibros 2019; 18: 525-529.

15 Reynaud Q, Poupon-Bourdy S, Rabilloud M, et al. Pregnancy outcome in women with cystic fibrosis-related diabetes. Acta Obstet Gynecol Scand 2017; 96: 1223-1227.

16 Kitzmiller JL, Gavin LA, Gin GD, et al. Preconception care of diabetes. Glycemic control prevents congenital anomalies. JAMA 1991; 265: 731-736.

17 Edenborough FP, Borgo G, Knoop C, et al. Guidelines for the management of pregnancy in women with cystic fibrosis. J Cyst Fibros 2008; 7: Suppl. 1, S2-32.

18 Moran A, Brunzell C, Cohen RC, et al. Clinical care guidelines for cystic fibrosis-related diabetes: a position statement of the American Diabetes Association and a clinical practice guideline of the Cystic Fibrosis Foundation, endorsed by the Pediatric Endocrine Society. Diabetes Care 2010; 33: 2697-2708.

19 Middleton PG, Wagenaar M, Matson AG, et al. Australian standards of care for cystic fibrosis-related diabetes. Respirology 2014; 19: 185-192.

20 Therapeutic Goods Administration. Australian Register of Therapeutic Goods: product name and formulation details. 2019. www.tga.gov.au/artg Date last accessed: March 1, 2019.

21 European Medicines Agency. Medicines. 2019. www.ema.europa.eu/en/medicines Date last accessed: March 1, 2019.

22 Food and Drug Administration. Labeling information for drug products. 2019. www.fda.gov/drugs/ development-resources/labeling-information-drug-products Date last accessed: March 1, 2019.

23 National Library of Medicine. Drugs and Lactation Database (LactMed). 2019. www.ncbi.nlm.nih.gov/books/ NBK501200 Date last accessed: March 1, 2019

24 Briggs GG, Freeman RK, Yaffe SL. Drugs in Pregnancy and Lactation: A Reference Guide to Fetal and Neonatal Risk. 10th Edn. Philadelphia, Wolters Kluwer Health, 2015.

25 Schaefer C, Peters PWJ, Miller RK. Drugs During Pregnancy and Lactation: Treatment Options and Risk Assessment. 3rd Edn. Amsterdam, Elsevier Science, 2015.

26 Eltonsy S, Forget A, Blais L. Beta 2 -agonists use during pregnancy and the risk of congenital malformations. Birth Defects Res A Clin Mol Teratol 2011; 91: 937-947.

27 Murphy VE, Wang G, Namazy JA, et al. The risk of congenital malformations, perinatal mortality and neonatal hospitalisation among pregnant women with asthma: a systematic review and meta-analysis. Br J Obstet Gynaecol 2013; 120: 812-822.

28 Van Zutphen AR, Bell EM, Browne ML, et al. Maternal asthma medication use during pregnancy and risk of congenital heart defects. Birth Defects Res A Clin Mol Teratol 2015; 103: 951-961.

29 Garne E, Vinkel Hansen A, Morris J, et al. Risk of congenital anomalies after exposure to asthma medication in the first trimester of pregnancy - a cohort linkage study. Br J Obstet Gynaecol 2016; 123: 1609-1618.

30 Gilchrist DM, Friedman JM, Werker D. Life-threatening status asthmaticus at 12.5 weeks gestation: report of a normal pregnancy outcome. Chest 1991; 100: 285-286.

31 Yeh TF, Pildes RS. Transplacental aminophylline toxicity in a neonate. Lancet 1977; 309: 910.

32 Norjavaara E, de Verdier MG. Normal pregnancy outcomes in a population-based study including 2968 pregnant women exposed to budesonide. J Allergy Clin Immunol 2003; 111: 736-742.

33 Rahimi R, Nikfar S, Abdollahi M. Meta-analysis finds use of inhaled corticosteroids during pregnancy safe: a systematic meta-analysis review. Hum Exp Toxicol 2006; 25: 447-452.

34 Blais L, Beauchesne MF, Lemiere C, et al. High doses of inhaled corticosteroids during the first trimester of pregnancy and congenital malformations. J Allergy Clin Immunol 2009; 124: 1229-1234.

35 Katz VL, Thorp JM Jr, Bowes WA Jr. Severe symmetric intrauterine growth retardation associated with the topical use of triamcinolone. Am J Obstet Gynecol 1990; 162: 396-397.

36 Chi CC, Mayon-White RT, Wojnarowska FT. Safety of topical corticosteroids in pregnancy: a population-based cohort study. I Invest Dermatol 2011; 131: 884-891.

37 Czeizel AE, Rockenbauer M. Population-based case-control study of teratogenic potential of corticosteroids Teratology 1997; 56: 335-340.

38 Park-Wyllie L, Mazzotta P, Pastuszak A, et al. Birth defects after maternal exposure to corticosteroids: prospective cohort study and meta-analysis of epidemiological studies. Teratology 2000; 62: 385-392.

39 Schatz M, Zeiger RS, Harden K, et al. The safety of asthma and allergy medications during pregnancy. J Allergy Clin Immunol 1997; 100: 301-306.

40 Bakhireva LN, Jones KL, Schatz M, et al. Asthma medication use in pregnancy and fetal growth. J Allergy Clin Immunol 2005; 116: 503-509.

41 Sarkar M, Koren G, Kalra S, et al. Montelukast use during pregnancy: a multicentre, prospective, comparative study of infant outcomes. Eur J Clin Pharmacol 2009; 65: 1259-1264.

42 Cavero-Carbonell C, Vinkel-Hansen A, Rabanque-Hernandez MJ, et al. Fetal exposure to montelukast and congenital anomalies: a population based study in Denmark. Birth Defects Res 2017; 109: 452-459.

43 Datta P, Rewers-Felkins K, Baker T, et al. Transfer of montelukast into human milk during lactation. Breastfeed Med 2017; 12: 54-57.

44 Heinonen OP, Slone D, Shapiro S. Birth Defects and Drugs in Pregnancy. Littleton, Publishing Sciences Group, 1977. 
Diav-Citrin O, Shechtman S, Aharonovich A, et al. Pregnancy outcome after gestational exposure to loratadine or antihistamines: a prospective controlled cohort study. J Allergy Clin Immunol 2003; 111: 1239-1243.

Weber-Schoendorfer C, Schaefer C. The safety of cetirizine during pregnancy. A prospective observational cohort study. Reprod Toxicol 2008; 26: 19-23.

Schwarz EB, Moretti ME, Nayak S, et al. Risk of hypospadias in offspring of women using loratadine during pregnancy: a systematic review and meta-analysis. Drug Saf 2008; 31: 775-788.

Gilboa SM, Strickland MJ, Olshan AF, et al. Use of antihistamine medications during early pregnancy and isolated major malformations. Birth Defects Res A Clin Mol Teratol 2009; 85: 137-150.

Lind JN, Tinker SC, Broussard CS, et al. Maternal medication and herbal use and risk for hypospadias: data from the National Birth Defects Prevention Study, 1997-2007. Pharmacoepidemiol Drug Saf 2013; 22: 783-793.

Li Q, Mitchell AA, Werler MM, et al. Assessment of antihistamine use in early pregnancy and birth defects. J Allergy Clin Immunol Pract 2013; 1: 666-674.

Golembesky A, Cooney M, Boev R, et al. Safety of cetirizine in pregnancy. J Obstet Gynaecol 2018; 38: 940-945.

Zierler S, Purohit D. Prenatal antihistamine exposure and retrolental fibroplasia. Am J Epidemiol 1986; 123: 192-196.

Hirashima J, Hojo M, Iikura M, et al. [A case of an asthma patient receiving omalizumab during pregnancy]. Arerugi 2012; 61: 1683-1687.

Kupryś-Lipińska I, Tworek D, Kuna P. Omalizumab in pregnant women treated due to severe asthma: two case reports of good outcomes of pregnancies. Postepy Dermatol Alergol 2014; 31: 104-107.

Namazy J, Cabana MD, Scheuerle AE, et al. The Xolair Pregnancy Registry (EXPECT): the safety of omalizumab use during pregnancy. J Allergy Clin Immunol 2015; 135: 407-412.

Kaminski R, Nazareth D. A successful uncomplicated CF pregnancy while remaining on Ivacaftor. J Cyst Fibros 2016; 15: 133-134.

Ladores S, Kazmerski TM, Rowe SM. A case report of pregnancy during use of targeted therapeutics for cystic fibrosis. J Obstet Gynecol Neonatal Nurs 2017; 46: 72-77.

Trimble A, McKinzie C, Terrell M, et al. Measured fetal and neonatal exposure to Lumacaftor and Ivacaftor during pregnancy and while breastfeeding. J Cyst Fibros 2018; 17: 779-782.

Lin KJ, Mitchell AA, Yau WP, et al. Maternal exposure to amoxicillin and the risk of oral clefts. Epidemiology 2012; 23: 699-705.

Kenyon S, Taylor DJ, Tarnow-Mordi WO, et al. ORACLE - antibiotics for preterm prelabour rupture of the membranes: short-term and long-term outcomes. Acta Paediatr Suppl 2002; 91: 12-15.

Lund M, Pasternak B, Davidsen RB, et al. Use of macrolides in mother and child and risk of infantile hypertrophic pyloric stenosis: nationwide cohort study. BMJ 2014; 348: g1908.

Loebstein R, Addis A, Ho E, et al. Pregnancy outcome following gestational exposure to fluoroquinolones: a multicenter prospective controlled study. Antimicrob Agents Chemother 1998; 42: 1336-1339.

Hernandez-Diaz S, Werler MM, Walker AM, et al. Folic acid antagonists during pregnancy and the risk of birth defects. N Engl J Med 2000; 343: 1608-1614.

Ford N, Shubber Z, Jao J, et al. Safety of cotrimoxazole in pregnancy: a systematic review and meta-analysis J Acquir Immune Defic Syndr 2014; 66: 512-521.

Hansen C, Andrade SE, Freiman H, et al. Trimethoprim-sulfonamide use during the first trimester of pregnancy and the risk of congenital anomalies. Pharmacoepidemiol Drug Saf 2016; 25: 170-178.

Kallen BA, Otterblad Olausson P, Danielsson BR. Is erythromycin therapy teratogenic in humans? Reprod Toxicol 2005; 20: 209-214.

Steen JS, Stainton-Ellis DM. Rifampicin in pregnancy. Lancet 1977; 2: 604-605.

Czeizel AE, Rockenbauer M, Olsen J, et al. A population-based case-control study of the safety of oral anti-tuberculosis drug treatment during pregnancy. Int J Tuberc Lung Dis 2001; 5: 564-568.

Jones HC. Intrauterine ototoxicity. A case report and review of literature. J Natl Med Assoc 1973; 65: 201-203. nephrotoxicity in the infant? Am J Obstet Gynecol 1989; 161: 977-981.

Mueller M, Balasegaram M, Koummuki Y, et al. A comparison of liposomal amphotericin B with sodium stibogluconate for the treatment of visceral leishmaniasis in pregnancy in Sudan. J Antimicrob Chemother 2006; 58: 811-815.

Lopez-Rangel E, Van Allen MI. Prenatal exposure to fluconazole: an identifiable dysmorphic phenotype. Birth Defects Res A Clin Mol Teratol 2005; 73: 919-923.

Aschenbrenner DS. The FDA reevaluates oral fluconazole use in pregnancy. Am J Nurs 2016; 116: 22.

Pilmis B, Jullien V, Sobel J, et al. Antifungal drugs during pregnancy: an updated review. J Antimicrob Chemother 2015; 70: 14-22.

Shoai Tehrani M, Sicre de Fontbrune F, Roth P, et al. Case report of exposure to voriconazole in the second and third trimesters of pregnancy. Antimicrob Agents Chemother 2013; 57: 1094-1095.

National Academy of Sciences. Dietary Reference Intakes for Vitamin A, Vitamin K, Arsenic, Boron, Chromium, Copper, Iodine, Iron, Manganese, Molybdenum, Nickel, Silicon, Vanadium, and Zinc. Washington, National Academies Press, 2001.

Garbis H, Elefant E, Diav-Citrin O, et al. Pregnancy outcome after exposure to ranitidine and other $\mathrm{H}_{2}$-blockers. A collaborative study of the European Network of Teratology Information Services. Reprod Toxicol 2005; 19: 453-458. Matok I, Gorodischer R, Koren G, et al. The safety of $\mathrm{H}_{2}$-blockers use during pregnancy. J Clin Pharmacol 2010; 50: 81-87.

Gill SK, O'Brien L, Einarson TR, et al. The safety of proton pump inhibitors (PPIs) in pregnancy: a meta-analysis. Am J Gastroenterol 2009; 104: 1541-1545.

Kallen B. Delivery outcome after the use of acid-suppressing drugs in early pregnancy with special reference to omeprazole. Br J Obstet Gynaecol 1998; 105: 877-881.

Anderka M, Mitchell AA, Louik C, et al. Medications used to treat nausea and vomiting of pregnancy and the risk of selected birth defects. Birth Defects Res A Clin Mol Teratol 2012; 94: 22-30.

Vargas FR, Schuler-Faccini L, Brunoni D, et al. Prenatal exposure to misoprostol and vascular disruption defects: a case-control study. Am J Med Genet 2000; 95: 302-306. 
Powell H, Murphy VE, Taylor DR, et al. Management of asthma in pregnancy guided by measurement of fraction of exhaled nitric oxide: a double-blind, randomised controlled trial. Lancet 2011; 378: 983-990.

Reddel HK, Bateman ED, Becker A, et al. A summary of the new GINA strategy: a roadmap to asthma control. Eur Respir J 2015; 46: 622-639.

Powell H, Murphy VE, Hensley MJ, et al. Rhinitis in pregnant women with asthma is associated with poorer asthma control and quality of life. J Asthma 2015; 52: 1023-1030.

Murphy VE, Jensen ME, Powell $\mathrm{H}$, et al. Influence of maternal body mass index and macrophage activation on asthma exacerbations in pregnancy. J Allergy Clin Immunol Pract 2017; 5: 981-987.

Williams MA, Gelaye B, Qiu C, et al. Habitual snoring and asthma comorbidity among pregnant women. J Asthma 2011; 48: 91-97.

Murphy VE, Clifton VL, Gibson PG. The effect of cigarette smoking on asthma control during exacerbations in pregnant women. Thorax 2010; 65: 739-744.

Murphy VE, Powell $\mathrm{H}$, Wark PAB, et al. A prospective study of respiratory viral infection in pregnant women with and without asthma. Chest 2013; 144: 420-427.

Murphy VE, Gibson PG, Talbot PI, et al. Asthma self-management skills and the use of asthma education during pregnancy. Eur Respir J 2005; 26: 435-441.

Robijn AL, Jensen ME, Gibson PG, et al. Trends in asthma self-management skills and inhaled corticosteroid use during pregnancy and postpartum from 2004 to 2017. J Asthma 2019; 56: 594-602.

Gluck JC, Gluck P. The effects of pregnancy on asthma: a prospective study. Ann Allergy 1976; 37: 164-168.

Gluck JC, Gluck PA. The effect of pregnancy on the course of asthma. Immunol Allergy Clin North Am 2006; 26 : 63-80.

Schatz M, Harden K, Forsythe A, et al. The course of asthma during pregnancy, post partum, and with successive pregnancies: a prospective analysis. J Allergy Clin Immunol 1988; 81: 509-517.

Gluck JC. The change of asthma course during pregnancy. Clin Rev Allergy Immunol 2004; 26: 171-180.

Gluck PA, Gluck JC. Asthma in women: special considerations. Ann Allergy Asthma Immunol 2006; 96: 635.

Grosso A, Locatelli F, Gini E, et al. The course of asthma during pregnancy in a recent, multicase-control study on respiratory health. Allergy Asthma Clin Immunol 2018; 14: 16.

Murphy VE, Clifton VL, Gibson PG. Asthma exacerb
adverse pregnancy outcomes. Thorax 2006; 61: 169-176. Bateman ED, Hurd SS, Barnes PJ, et al. Global strategy for asthma management and prevention: GINA executive summary. Eur Respir J 2008; 31: 143-178.

National Asthma Education and Prevention Program. NAEPP Expert Panel Report. Managing asthma during pregnancy: recommendations for pharmacologic treatment - 2004 update. J Allergy Clin Immunol 2005; 115: 34-46. McLaughlin K, Kable A, Ebert L, et al. Midwives' perception of their role in providing antenatal asthma management in Australia - a qualitative study. Midwifery 2016; 35: 11-16.

Murphy VE, Namazy JA, Powell H, et al. A meta-analysis of adverse perinatal outcomes in women with asthma. Br J Obstet Gynaecol 2011; 118: 1314-1323.

Namazy JA, Murphy VE, Powell H, et al. Effects of asthma severity, exacerbations and oral corticosteroids on perinatal outcomes. Eur Respir J 2013; 41: 1082-1090.

Murphy VE, Schatz M. Asthma in pregnancy: a hit for two. Eur Respir Rev 2014; 23: 64-68.

Wang G, Murphy VE, Namazy J, et al. The risk of maternal and placental complications in pregnant women with asthma: a systematic review and meta-analysis. J Matern Fetal Neonatal Med 2014; 27: 934-942.

Morten M, Collison A, Murphy VE, et al. Managing Asthma in Pregnancy (MAP) trial: $\mathrm{F}_{\mathrm{ENO}}$ levels and childhood asthma. J Allergy Clin Immunol 2018; 142: 1765-1772.

Blais L, Beauchesne MF, Rey E, et al. Use of inhaled corticosteroids during the first trimester of pregnancy and the risk of congenital malformations among women with asthma. Thorax 2007; 62: 320-328.

Eltonsy S, Forget A, Beauchesne MF, et al. Risk of congenital malformations for asthmatic pregnant women using a long-acting beta 2 -agonist and inhaled corticosteroid combination versus higher-dose inhaled corticosteroid monotherapy. J Allergy Clin Immunol 2015; 135: 123-130.

Huang L, Fan L, Ding P, et al. The mediating role of placenta in the relationship between maternal exercise during pregnancy and full-term low birth weight. J Matern Fetal Neonatal Med 2018; 31: 1561-1567.

Daly N, Farren M, McKeating A, et al. A medically supervised pregnancy exercise intervention in obese women: a randomized controlled trial. Obstet Gynecol 2017; 130: 1001-1010.

Jensen ME, Murphy VE, Gibson PG, et al. Vitamin D status in pregnant women with asthma and its association with adverse respiratory outcomes during infancy. J Matern Fetal Neonatal Med 2019; 32: 1820-1825.

Hornsby E, Pfeffer PE, Laranjo N, et al. Vitamin D supplementation during pregnancy: effect on the neonatal immune system in a randomized controlled trial. J Allergy Clin Immunol 2018; 141: 269-278.

van Odijk J, Kull I, Borres MP, et al. Breastfeeding and allergic disease: a multidisciplinary review of the literature (1966-2001) on the mode of early feeding in infancy and its impact on later atopic manifestations. Allergy 2003; 58: 833-843.

Sears MR, Greene JM, Willan AR, et al. Long-term relation between breastfeeding and development of atopy and asthma in children and young adults: a longitudinal study. Lancet 2002; 360: 901-907.

McLaughlin K, Foureur M, Jensen ME, et al. Review and appraisal of guidelines for the management of asthma during pregnancy. Women Birth 2018; 31: e349-e357.

Gilljam M, Antoniou M, Shin J, et al. Pregnancy in cystic fibrosis. Fetal and maternal outcome. Chest 2000; 118: $85-91$.

Siegel B, Siegel S. Pregnancy and delivery in a patient with cystic fibrosis of the pancreas: report of a case. Obstet Gynecol 1960; 16: 438-440.

Cohen LF, di Sant'Agnese PA, Friedlander J. Cystic fibrosis and pregnancy: a national survey. Lancet 1980; 316: 842-844.

Edenborough FP, Mackenzie WE, Stableforth DE. The outcome of 72 pregnancies in 55 women with cystic fibrosis in the United Kingdom 1977-1996. Br J Obstet Gynaecol 2000; 107: 254-261.

in AC, Sharshiner R, Caughey AB. Maternal co-morbidities and neonatal outcomes associated with cystic fibrosis. J Matern Fetal Neonatal Med 2017; 30: 4-7. 
121 Palmer J, Dillon-Baker C, Tecklin JS, et al. Pregnancy in patients with cystic fibrosis. Ann Intern Med 1983; 99: 596-600.

122 Canny GJ. Pregnancy in patients with cystic fibrosis. Can Med Assoc J 1993; 149: 805-806.

123 Jankelson D, Robinson M, Parsons S, et al. Cystic fibrosis and pregnancy. Aust NZ J Obstet Gynaecol 1998; 38: 180-184.

124 Goss CH, Rubenfeld GD, Otto K, et al. The effect of pregnancy on survival in women with cystic fibrosis. Chest 2003; 124: 1460-1468.

125 Schechter MS, Quittner AL, Konstan MW, et al. Long-term effects of pregnancy and motherhood on disease outcomes of women with cystic fibrosis. Ann Am Thorac Soc 2013; 10: 213-219.

126 Thorpe-Beeston JG, Madge S, Gyi K, et al. The outcome of pregnancies in women with cystic fibrosis - single centre experience 1998-2011. Br J Obstet Gynaecol 2013; 120: 354-361.

127 Bose D, Yentis SM, Fauvel NJ. Caesarean section in a parturient with respiratory failure caused by cystic fibrosis. Anaesthesia 1997; 52: 578-582.

Frangolias DD, Nakielna EM, Wilcox PG. Pregnancy and cystic fibrosis: a case-controlled study. Chest 1997; 111: 963-969.

129 Tanser SJ, Hodson ME, Geddes DM. Case reports of death during pregnancy in patients with cystic fibrosis three out of four patients were colonized with Burkholderia cepacia. Respir Med 2000; 94: 1004-1006.

130 Goss CH, VanDevanter DR. CFTR modulators and pregnancy: our work has only just begun. J Cyst Fibros 2016; 15: 6-7.

131 Heltshe SL, Godfrey EM, Josephy T, et al. Pregnancy among cystic fibrosis women in the era of CFTR modulators. J Cyst Fibros 2017; 16: 687-694.

132 UK Chief Medical Officer. Physical activity in pregnancy. 2016. www.gov.uk/government/publications/ start-active-stay-active-infographics-on-physical-activity Date last accessed: October 19, 2019.

133 Button BM, Wilson C, Dentice R, et al. Physiotherapy for cystic fibrosis in Australia and New Zealand: a clinical practice guideline. Respirology 2016; 21: 656-667.

134 Button B. Physiotherapy during pregnancy, labour and the post-natal period. 2018. https://www.ecfs.eu/sites/ default/files/general-content-files/working-groups/IPG\%20CF_Blue\%20Booklet_7th\%20edition\%202019.pdf Date last accessed: October 19, 2019.

135 Gyi KM, Hodson ME, Yacoub MY. Pregnancy in cystic fibrosis lung transplant recipients: case series and review. J Cyst Fibros 2006; 5: 171-175.

136 Shaner J, Coscia LA, Constantinescu S, et al. Pregnancy after lung transplant. Prog Transplant 2012; 22: 134-140.

137 Howie AD, Milne JA. Pregnancy in patients with bronchiectasis. Br J Obstet Gynaecol 1978; 85: 197-200.

138 Afzelius BA, Eliasson R. Male and female infertility problems in the immotile-cilia syndrome. Eur J Respir Dis Suppl 1983; 127: 144-147.

139 Elkus R, Popovich J Jr. Respiratory physiology in pregnancy. Clin Chest Med 1992; 13: 555-565.

140 Johannesson M. Effects of pregnancy on health: certain aspects of importance for women with cystic fibrosis. J Cyst Fibros 2002; 1: 9-12.

141 Stenius-Aarniala B, Piirila P, Teramo K. Asthma and pregnancy: a prospective study of 198 pregnancies. Thorax 1988; 43: 12-18.

142 Dombrowski MP, Schatz M, Wise R, et al. Asthma and pregnancy. Obstet Gynecol 2004; 103: 5-12.

143 Mabie WC, Barton JR, Wasserstrum N, et al. Clinical observations on asthma in pregnancy. J Matern Fetal Med 1992; 1: 45-50.

144 Lao TT, Huengsburg M. Labour and delivery in mothers with asthma. Eur J Obstet Gynecol Reprod Biol 1990; 35: 183-190.

145 Kahr N, Naeser V, Stensballe LG, et al. Gene-environment interaction in atopic diseases: a population-based twin study of early-life exposures. Clin Respir J 2015; 9: 79-86.

146 Juhn Y, Weaver A, Katusic S, et al. Mode of delivery at birth and development of asthma: a population-based cohort study. J Allergy Clin Immunol 2005; 116: 510-516.

147 British Thoracic Society/Scottish Intercollegiate Guidelines Network. British guideline on the management of asthma. 2016. www.sign.ac.uk/guidelines/fulltext/153/index.html Date last accessed: October 19, 2019.

148 Rooney Thompson M, Towers CV, Howard BC, et al. The use of prostaglandin $\mathrm{E}_{1}$ in peripartum patients with asthma. Am J Obstet Gynecol 2015; 212: 392.

149 Nandhakumar A, Silverman GL. Acute hypoxemia in a parturient with primary ciliary dyskinesia following the administration of intravenous oxytocin: a case report. Can J Anaesth 2013; 60: 1218-1221.

150 National Institute for Health and Care Excellence. Intrapartum care: care of healthy women and their babies during childbirth. CG190. 2014. www.nice.org.uk/guidance/cg190 Date last accessed: October 19, 2019.

151 Schatz M. Asthma during pregnancy: interrelationships and management. Ann Allergy 1992; 68: 123-133.

152 Kuczkowski KM. Labor analgesia for the parturient with respiratory disease: what does an obstetrician need to know? Arch Gynecol Obstet 2005; 272: 160-166.

153 Caughey AB, Parer JT. Tocolysis with beta-adrenergic receptor agonists. Semin Perinatol 2001; 25: 248-255.

154 Royal College of Obstetricians and Gynaecologists. Reducing the risk of venous thromboembolism during pregnancy and the puerperium. Green-Top Guideline 37a. 2015. www.rcog.org.uk/en/guidelines-researchservices/guidelines/gtg37a Date last accessed: October 19, 2019.

155 Shiffman ML, Seale TW, Flux M, et al. Breast-milk composition in women with cystic fibrosis: report of two cases and a review of the literature. Am J Clin Nutr 1989; 49: 612-617.

156 Holton S, Fisher J, Button B, et al. Childbearing concerns, information needs and preferences of women with cystic fibrosis: an online discussion group. Sex Reprod Healthc 2019; 19: 31-35. 